\title{
COVID-19 and Gastrointestinal Disease: Implications for the Gastroenterologist
}

\author{
Richard H. Hunt ${ }^{a}$ James E. East ${ }^{b}$ Angel Lanas ${ }^{c}$ Peter Malfertheiner ${ }^{d, e}$ \\ Jack Satsangif ${ }^{\mathrm{f} g}$ Carmelo Scarpignato ${ }^{\text {h, }}{ }^{\mathrm{i}}$ Gwilym J. Webb ${ }^{\mathrm{j}}$ \\ ${ }^{a}$ Farncombe Family Digestive Health Research Institute, Division of Gastroenterology, McMaster University, \\ Hamilton, ON, Canada; ${ }^{\mathrm{b}}$ Translational Gastroenterology Unit, Experimental Medicine Division, Nuffield Department \\ of Medicine, John Radcliffe Hospital, University of Oxford, Oxford, UK; ' University Hospital Lozano Blesa, IIS Aragón, \\ CIBER Enfermedades Hepáticas y Digestivas (CIBERehd) Digestive Diseases, Universidad de Zaragoza, \\ Zaragoza, Spain; ${ }^{d}$ Klinik für Gastroenterologie, Hepatologie und Infektiologie, Otto-von-Guericke-Universität, \\ Magdeburg, Germany; ${ }^{\mathrm{e}}$ Med. Klinik und Poliklinik II, Klinikum der Universität, Ludwig Maximilian University of \\ Munich, Munich, Germany; ${ }^{f}$ Consultant Physician, Oxford University NHS Trust and Translational Gastroenterology \\ Unit, Experimental Medicine Division, Nuffield Department of Medicine, University of Oxford, Oxford, UK; \\ ${ }^{9}$ Department of Gastroenterology, University of Edinburgh, Edinburgh, UK; ${ }^{\mathrm{h}}$ Department of Health Sciences,

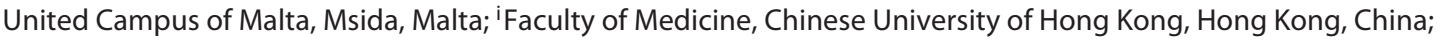 \\ jOxford Liver Unit, Translational Gastroenterology Unit, Oxford University Hospitals, Oxford, UK
}

\section{Keywords}

Inflammatory bowel disease · Liver · Pancreas .

Gastrointestinal tract · COVID-19 · Pathophysiology ·

Endoscopy $\cdot$ Management $\cdot$ Review

\begin{abstract}
Background: COVID-19 was initially considered a respiratory disease but the SARS-CoV-2 virus can lead to serious systemic consequences affecting major organs including the digestive system. Summary: This review brings new clinically important information for the gastroenterologist. This includes: the mechanisms of tissue damage seen with the SARS-CoV-2 virus; the consequences of immunosuppression in patients with inflammatory bowel disease (IBD) and chronic liver disease with the additional risks of decompensation in patients with cirrhosis; the impact of COVID-19 on gastrointestinal
\end{abstract}

emergencies, on gastrointestinal endoscopy, diagnosis and treatments. These highlight the need to understand the clinical pharmacology, toxicology and therapeutic implications of drugs commonly used by gastroenterologists and their links with COVID-19. Key Messages: Any part of the digestive system may be affected by the SARS-CoV-2 virus, and those with pre-existing disease are at greatest risk of adverse outcomes. The risk for drug-drug interactions is considerable in patients seriously ill with COVID-19 who often require mechanical ventilation and life support. Some repurposed drugs used against SARS-CoV-2 can cause or aggravate some of the COVID-19-related gastrointestinal symptoms and can also induce liver injury. Ongoing clinical studies will hopefully identify effective drugs with a more favourable riskbenefit ratio than many initially tried treatments.

(c) 2020 S. Karger AG, Basel

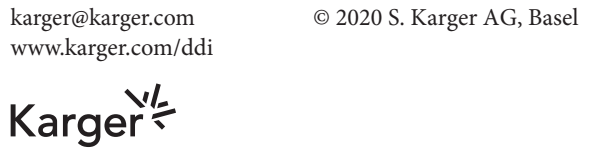




\section{Introduction to COVID-19}

The pandemic caused by the novel SARS-CoV-2 virus has led to the disease now termed COVID-19 by the WHO [1]. This has been followed by an explosion of information about this novel virus much of which is important and clinically relevant to gastroenterologists. COVID-19 was originally considered a respiratory disease but increasing evidence identified the potentially serious systemic consequences involving major organs, including those of the digestive system. This review brings together the salient information relating to the digestive system, published up to September 2020. At the time of acceptance (October 2020), more than 43 million cases of COVID-19 have been reported worldwide with over 1 million deaths [2]. SARS-CoV-2 is a single-stranded RNA virus, initially described as a serious acute respiratory virus of the coronavirus (SARS) family [3] and is similar to those viruses which caused the 2002-2004 SARS epidemic, originating in China, and the 2012-2020 MERS outbreaks in the Middle East. COVID-19 is closely related to bat coronaviruses, suggesting COVID-19 has a similar zoonotic origin. The virus is highly contagious and spreads predominantly by respiratory droplets and aerosol while SARS-CoV-2 has been isolated from stool but faecal-oral spread has not been confirmed to date.

\section{Symptoms and Clinical Presentations}

The predominant symptoms of COVID-19 infection in one large UK series of more than 20,000 hospitalized patients were fever $(71.6 \%)$, cough $(68.9 \%)$ and shortness of breath (71.2\%), which reflect the case definition [4]. Only $4.5 \%$ presented without symptoms at the time of admission.

However, 3 other symptom clusters were recognized including firstly, myalgia, joint pain, headache and fatigue and secondly abdominal pain, nausea and vomiting and diarrhoea. $29 \%$ of all patients reported these enteric symptoms, mostly in addition to the respiratory symptoms, and only $4 \%$ complained of enteric symptoms alone.

Han et al. [5], from Wuhan, the epicentre of the global pandemic, describe a unique subgroup of $206 \mathrm{COV}$ ID-19 patients presenting to hospital, 48 (23\%) with one or more of only digestive symptoms of diarrhoea, nausea and vomiting and 69 with or 48 without respiratory symptoms and compared them with a group of 89 with solely respiratory symptoms. An important clinical consider- ation is whether these symptoms are primarily associated with COVID-19 or are a consequence of treatment (see below).

In this study [5], 67 patients presented with diarrhoea, which was the first symptom of the illness in $19.4 \%$ and lasted from 1 to 14 days (average $5.4 \pm 3.1$ days and with $4.2 \pm 2.2$ bowel movements/day) [5]. Fever was present in $62.4 \%$ of those with enteric symptoms, and patients presented significantly later than those with respiratory symptoms ( $16.0 \pm 7.7$ vs. $11.6 \pm 5.1$ days, $p<0.001)$. Patients with digestive symptoms also had a longer duration between onset of symptoms and viral clearance $(p<$ 0.001 ) and were more likely to have a virus (RT-PCR)positive stool test ( 73.3 vs. $14.3 \%, p=0.033$ ).

More recently, the symptoms of anosmia and dysgeusia have been added to the core symptoms of COVID-19 with olfactory dysfunction reported by $52.7 \%$ (95\% CI 29.6-75.2) and gustatory dysfunction by $43.9 \%$ (95\% CI 20.5-69.0\%) [6]. It is probable that these symptoms result from COVID-19 neuropathy with a point of entry being by way of angiotensin-converting enzyme 2 (ACE 2)-expressing cells (see below) in the olfactory epithelium and reaching the olfactory bulb via axons extending to the olfactory nucleus in the pyriform cortex $[7,8]$.

A systematic review and meta-analysis reported pooled detection rates for diarrhoea, nausea or vomiting and liver function tests outside the reference range and a positive SARS-CoV-2 faecal test [9]. There were 23 published and 6 preprint studies with 4,805 patients with a mean age of 52.2 years (SD 14.8), and 33.2\% were female. $7.4 \%$ (95\% CI 4.3-12.2\%) reported diarrhoea and 4.6\% (95\% CI 2.6$8.0 \%$ ) nausea or vomiting. $20 \%$ (95\% CI 15.3-25.6\%) had an aspartate aminotransferase and $14.6 \%$ (95\% CI $12.8-$ $16.6 \%)$ an alanine aminotransferase outside the normal range. A positive faecal test for SARS-CoV-2 was reported in 8 studies, and viral RNA was detected in stool in $40.5 \%$ (95\% CI 27.4-55.1\%) patients with a high level of heterogeneity. The SARS-CoV-2 virus has remained positive in stools even after respiratory tract specimens were negative for the virus [9]. A recent study from Hong Kong has shown a signature of active gastrointestinal (GI) tract viral infection in 7 out of $15(47 \%)$ patients with COVID-19 even in the absence of GI symptoms, which suggests quiescent infection with the SARS-CoV-2 virus [10]. The viral activity and replication in the gut persisted even after respiratory tract clearance of the virus. Such findings continue to support the concerns for faecal-oral spread of COVID-19 although this has not been confirmed to date (see discussion regarding colonoscopy below). 
Fig. 1. The dynamics of viral entry into human cells. Spike proteins on the surface of the SARS-CoV-2 bind to angiotensinconverting enzyme 2 (ACE 2) receptors on the surface of the target cell while the type II transmembrane serine protease (TMPRSS2) binds to and cleaves the ACE 2 receptor. In the process, the spike protein is activated. Cleaved ACE 2 and activated spike protein facilitate viral entry, leading to infection. Modified from https://www. eurekalert.org/pub_releases/2020-03/ tiom-nie032420.php

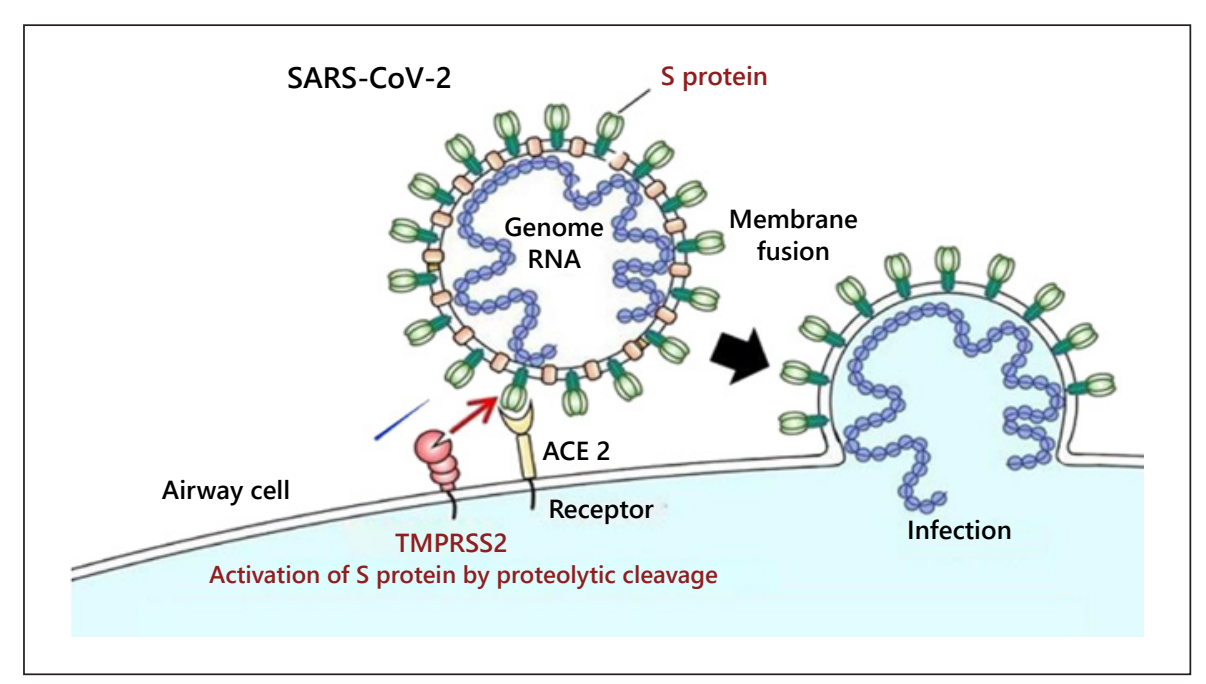

These studies suggest that GI symptoms are frequently seen in patients with COVID-19, although respiratory symptoms remain the predominant presentation.

\section{Pathogenesis}

The pathogenesis of SARS-CoV-2 is now increasingly well understood, and serious disease outcomes are dependent on the ability of the virus to bind to the ACE 2 receptor which facilitates entry into epithelial cells. This can lead in the lungs to a severe host hyperimmune response with a life-threatening cytokine storm resulting in the systemic inflammatory response syndrome $[11,12]$.

Virus entry into epithelial cells is achieved by way of the spike protein on the viral coat, which is primed by the cellular transmembrane serine protease 2 (TMPRSS-2) [13] shown in Figure 1.

In the gastrointestinal tract the mechanism is similar, and evidence for infection by SARS-CoV-2 has come from hospitalized patients who tested positive for the virus in stool. The ACE 2 receptor stained positive in the cytoplasm of GI epithelial cells, and staining for the viral nucleocapsid protein was present in the cytoplasm of gastric, duodenal and rectal glandular epithelial cells although not in oesophageal epithelium [14].

In inflammatory bowel disease (IBD), age, inflammation and disease location are critical determinants of intestinal expression of ACE 2 disease. ACE 2 expression in the terminal ileum of normal controls was higher than in the colon, and in IBD patients ACE 2 expression was also higher in the terminal ileum than the colon (see below) [15].

\section{IBD and the First Wave of the SARS-CoV-2 Pandemic}

The onset of the SARS-CoV-2 pandemic has had a dramatic and immediate impact in the field of IBD, affecting the daily lives of patients, carers, health care professionals, and the research and academic community. Clinical practice has required basic redesign and re-evaluation of fundamental principles involved in patient management. As the first wave of infection subsides, it is now apparent that some changes were necessary as short-term precautions that limited care, but other innovations such as the use of telemedicine, and non-invasive point-of-care biomarker analysis may need implementation into longterm management.

Inevitably, the first and overriding concern was to protect the safety of patients with IBD and their health care professionals and carers. Anxieties have been heightened by the widespread use of immune-modulator and biological agents in Crohn's disease and ulcerative colitis, when treatment goals now involve full remission and mucosal healing. With the pandemic imminent in Europe and North America, these issues were discussed by opinion leaders and expert IBD clinicians from these regions together with the highly influential International Organization for the Study of IBD group. A consensus emerged on the key issues $[16,17]$. It was widely held that continuing immune-active therapies, with strict attention to disinfection measures, social distancing and shielding where necessary, would be preferable to (indefinite) drug discontinuation, and the significant associated risk of relapse, the latter requiring investigation, hospital attendance and potentially more aggressive drug therapy or surgery. 
In the UK, a grid system to assess risk in any individual with IBD was developed by an invited group of experienced clinicians. Patients believed to be at highest risk (active disease, associated need for induction therapy with steroids or biological agents, elderly patients and those with comorbidities) required to quarantine ("shield"), with home deliveries of food and drugs, if necessary. Patients under monotherapy or combination therapy were advised to employ strict extended social distancing. Conventional clinics were stopped in favour of telemedicine, endoscopy restricted to emergency need, video-conferencing favoured for all clinical interaction where possible, and academic activities restricted. Research activities in the UK and elsewhere were limited to COVID-19-related studies, with ongoing trials accordingly affected.

Several research initiatives were established, including assessment of clinical experience. The SECURE registry, to monitor outcomes of COVID-19 in IBD patients worldwide, reported on 525 patients from 33 countries, with physician-based reporting of proven cases [18]. Multivariable and exploratory analyses identified factors that may influence severity of COVID-19 illness; importantly, the study was not designed to allow reporting of susceptibility to COVID-19, and data regarding disease activity were limited to a physician global assessment, rather than objective parameters. The fatality rate was only $3 \%$ (16 patients). On multivariable analysis the authors implicated age, comorbidity, use of steroids and mesalazine but not of biological monotherapy with the outcome parameter of ICU admission or death, and specifically, steroid use or advanced age with death. Tumour necrosis factor (TNF) monotherapy was not implicated in poor outcome; however, notably, on extended analyses, TNF combination therapies and mesalazine/5-aminosalicylic acid monotherapy were associated with the outcome of hospitalization or death.

The most recent updates to the SECURE-IBD registry [19] bring the total number of patients covered to over 2,280 . On univariate analysis, the drugs associated with highest risks of adverse outcomes - ICU care, ventilation and death - are those on corticosteroids (19\% of these patients developed adverse outcomes). In contrast, patients under monotherapy with either anti-TNF treatment or anti-interleukin-12/23 therapy were reported to have only a $2-3 \%$ risk of serious adverse outcomes.

These data are complementary to recent data from Germany demonstrating low seroprevalence rates in patients under anticytokine therapy. Global studies are under way in these patients to address this important issue
[20]. Several publications from centres in Europe and North America have reported on either prevalence of COVID-19 in IBD patients, development of severe complications or death, and assessed risk factors for these [21-23]. Broadly, a consensus emerges that mortality rates are not unduly increased in IBD compared with the populations studied, but advanced age, comorbid illness and active IBD, particularly colonic disease, are key concerns within this patient population. Most recently, these data are complemented by those from Wuhan. Stopping immune-modulation and biological agents in this setting was considered necessary early in the pandemic and was associated with very low rates of COVID-19, but followup data confirm that stopping these agents has already been associated with significant problems related to the management of disease relapse [24].

Dissecting the effects of individual drugs from undiagnosed active disease or other confounders related to study design is not straightforward, but clearly important [25]. Great concern surrounds the prior use of corticosteroids, and this is re-enforced by data from individual centres. As a counterpoint, however, the RECOVERY study makes a compelling case for the use of corticosteroids in severe COVID-19, and perhaps timing of steroid use, relative to infection, or relative to the development of a COVID-19-related "cytokine storm" will prove critical. Ongoing studies will determine whether anti-TNF monotherapy may have a beneficial effect on abrogating the immune-mediated lung and systemic damage in severe COVID-19 disease. Controversies regarding mesalazine therapy are unexpected, but in the SECURE-IBD registry [18] the odds ratio (OR) for mesalazine is 3.1 (95\% CI $1.3-7.7)$. It is unclear whether there are confounding issues or whether this may be a signal that needs detailed exploration [26].

Until more data are presented, it seems appropriate to advocate early and careful strategies for detection and treatment of active disease, limiting steroids if possible, using monotherapy with biological agents rather than combination therapy and otherwise observing conventional guidelines for drug management [25]. During the height of the pandemic, elective and emergency surgeries were associated with high complication rates, highlighting the need for targeted and effective medical interventions.

Mechanistic studies to assess risk factors for SARSCoV-2 infection within the IBD population have focussed on the regulation of the expression of the key molecules involved in viral recognition and epithelial cell entry, ACE 2 and TMPRSS2 in the ileum and colon, and wheth- 
er drugs used for IBD might alter this expression and increase vulnerability to local or systemic disease. Gene and protein expression data suggest that age, disease activity and disease location are key determinants, with confirmatory data demonstrating increased ACE 2 expression in active colonic disease and increased TMPRSS2 in ileal inflammation $[15,27]$. These data require functional exploration, as do the effects of specific drugs implicated in clinical data sets as potentially determining severity or susceptibility.

As the first wave of the pandemic resolves, new issues are surfacing in defining new parameters for resumption of "normal" life. For patients who have been in quarantine, there are inevitable concerns regarding socialization and re-integration, which require to be sensitively addressed as new data emerge. For clinicians, the need to resume safe delivery of optimum care is paramount, and as a key exemplar, endoscopic assessment and surveillance, and training and teaching, have been heavily impacted [28]. Academic activities, clinical trials and basic and translational laboratory research have all been paused, and major grant funding has been directed inevitably towards COVID-19 at the expense of other studies.

Clear benefits may follow from this worldwide crisis in health care. Telephone and video consultations have become popular among patients, clinicians and health care providers, as have strategies for telemonitoring such as the innovative True Colours programme [29]. The need for non-invasive point-of-care testing is apparent with associated research in biomarker discovery. Strategies for personalizing care and delivering stratified medicines to provide effective and safe medicines, whilst withdrawing ineffective therapies are also identified as a key unmet need and represent the focus for ongoing work.

\section{COVID-19 in Chronic Liver Disease}

Early reports of COVID-19 described frequent derangements of liver chemistry together with a correlation between changes and disease severity, so raising concerns of direct hepatic injury [30,31]. Most prominent were elevations of serum transaminase activity, with mild jaundice in a minority but only very few patients developing impaired synthetic function. Further, some authors described hepatocyte apoptosis with mitochondrial swelling, endoplasmic reticulum dilatation and glycogen granule decrease together with widespread necrosis in patients with fatal COVID-19 [32]. However, other autopsy and biopsy studies have reported that, whilst SARS-CoV-2
RNA is present in the livers of COVID-19 patients [33], histological findings were primarily consistent with shock liver [34] or pre-existing liver disease [35]. It has been suggested that the histological changes reported in early severe cases are in fact best explained by the effects of a cytokine storm [36]. Consistent with this interpretation of indirect hepatic injury are the observations that hepatic ACE 2 receptor expression is biliary not hepatocellular, and that both biochemical cholestasis and histological biliary damage are uncommon in COVID-19 [37-39].

Whether patients with pre-existing chronic liver disease (CLD) with COVID-19 present with a different clinical syndrome from those without CLD remains unclear. Symptoms reported to date appear broadly consistent, although perhaps with more prominent gastrointestinal involvement in CLD [40]. Outcome data in CLD patients with SARS-CoV-2 infection are still being collected but appear to indicate a greatly increased risk of death, and that this risk increases with severity of liver disease such as increased Child-Turcotte-Pugh class or model for endstage liver disease [40-42]. Supporting these primarily hospital-derived studies is the observation that undifferentiated CLD is associated with an approximately $60 \%$ increase in risk of death from population baseline in a large primary care cohort study [43]. A key challenge in interpreting such studies is, however, accounting for concurrent risk from comorbidities such as obesity and other metabolic factors [44], and also in accounting for the correlations between cirrhosis and other major risk factors for COVID-19 outcome, such as deprivation and associations with ethnicity [45]. In addition to poorer outcomes from COVID-19, frequent hepatic decompensation is reported amongst patients with pre-existing cirrhosis [4042]; consistent with this, guidelines recommend SARS$\mathrm{CoV}-2$ testing in hepatic decompensation even in the absence of respiratory symptoms [46-48].

The effects of the SARS-CoV-2 pandemic on health care provision are wide-ranging and likely to affect the care of patients with CLD with, as yet, unquantified effects on hepatocellular carcinoma surveillance, oesophageal variceal surveillance, viral hepatitis care, and immunosuppressive treatment regimens (e.g., greater use of budesonide in preference to prednis(ol)one) for patients with autoimmune disease [49-51]. Further, increased alcohol consumption, drug use and rates of obesity are forecast following the epidemic and may be predicted to fuel the development of further CLD $[52,53]$. Reductions in organ availability, pressure on intensive care beds and altered prioritization schedules have already affected those CLD patients awaiting transplantation [54]. 
At present, remdesivir and dexamethasone represent the two major drug options for COVID-19 [55-57]. Despite no significant differences in biochemical liver injury compared with placebo in one trial [54], cirrhosis patients and those with significant elevations of transaminase activities were excluded from recruitment to the major study on remdesivir, and currently patients with decompensated cirrhosis and transaminase elevations $>5 \times \mathrm{ULN}$ are recommended not to receive remdesivir $[55,56]$. Reactivation of chronic hepatitis $B$ with dexamethasone therapy must be considered, especially where the virus is endemic $[57,58]$. The reported benefit from corticosteroid therapy highlights the uncertainty regarding the relative risk of COVID-19 to CLD patients requiring immunosuppression, particularly those with autoimmune hepatitis, where data to guide care are urgently needed [50].

Management of immunosuppressive therapy and drug-drug interactions (DDIs) in patients with a history of liver transplantation, infected with COVID-19, must be balanced to permit an adequate immune response whilst avoiding rejection. Reducing immunosuppression to the most acceptable has been proposed, especially in the setting of lymphopenia or worsening infection, although evidence to guide such dose adjustments is lacking and, indeed, routine reduction is currently advised against by major guidelines [46-48]. In a series of 151 liver transplant patients with SARS-CoV-2 infection, there was no increase in mortality compared to age-, sexand comorbidity-matched controls [59]. Moreover, a nationwide study from Spain supports these findings of no apparent additional risk to those with a liver transplant [60]. DDIs between COVID-19 repurposed drugs and immunosuppressants in liver transplant recipients may have deleterious consequences [61]. Chloroquine-based regimes or remdesivir appear to be safe, while boosted protease inhibitors should be avoided [62].

COVID-19 is negatively affecting patients with liver malignancies. A multidisciplinary team [63] reviewed the standard management options for hepatocellular carcinoma and proposed treatment recommendations related to COVID-19 for the different stages of hepatocellular carcinoma in relation to surgery, locoregional and systemic therapies. When resection is unavailable, alternatives for cholangiocarcinoma include systemic therapy, local ablative therapies, transarterial radioembolization with deferred resection and surveillance [63].

From the perspective of the liver, SARS-CoV-2 seems to be primarily of indirect concern: evidence for direct injury to the liver is limited but those with advanced cir- rhosis appear at risk of decompensation and death from the systemic response seen in COVID-19; the indirect effects of the pandemic seem likely to have major effects on liver patients in impeding standard clinical care and in creating conditions conducive to the development of additional CLD.

\section{COVID-19 and the Upper Gastrointestinal Tract}

Early reports from China, all based on retrospective data, reported the prevalence of GI symptoms in COVID-19 cases between 11.4 and 50\% [64, 65]. In a metaanalysis involving over 4,000 patients, the prevalence of GI symptoms was $17 \%$ [66]. GI symptoms presenting as an initial symptom cluster of COVID-19 infection has been reported in 3 up to $10 \%$ of adult patients and more frequently in children. Although upper GI symptoms are frequently present, the most serious GI symptom in the context of COVID-19 is severe diarrhoea.

Oesophageal symptoms directly associated with the SARS-CoV-2 infection are not reported but heartburn is frequent, as in the general population and requires a standard approach with proton pump inhibitors (PPIs) or $\mathrm{H}_{2}$ receptor antagonists $\left(\mathrm{H}_{2} \mathrm{RAs}\right)$. The observation of an apparent clinical benefit with famotidine in COVID-19 patients, who were taking the drug for acid-related reflux, prompted a small study which reported an improved clinical outcome in COVID-19 patients [67], further confirmed in a propensity score matched retrospective cohort study [68]. The controversial observations concerning negative effects of PPI use and COVID-19 and these positive results with famotidine are addressed under pharmacotherapeutic considerations for GI treatments in COVID-19 patients.

Upper GI tract symptoms may include loss of appetite (anorexia), nausea, vomiting and/or abdominal pain.

Anorexia is the most frequently reported symptom, although it is quite non-specific. Among the mechanisms considered are the systemic inflammation and malaise (fatigue) associated with the SARS-CoV-2 infection and also the need for various medications, which may include analgesics, antipyretics, antibiotics etc (see below). Neurosensory effects such as dysgeusia and anosmia are often reported in patients with a mild clinical course [69] and may contribute to diminished appetite and even nausea.

Direct functional damage of the GI tract by viral interaction with the squamous and columnar epithelium mediated by ACE 2 receptor interference is likely to occur. However, the expression of ACE 2 receptors is signifi- 
cantly lower or absent in the oesophagus and stomach as compared to the intestine $[13,70,71]$.

A lower expression in the oesophageal and gastric as compared to intestinal mucosa is also true for the serine protease complex TMPRSS2 [71]. So, although direct viral damage is thought to occur primarily in the small and large bowel, it does not exclude an origin for abdominal symptoms referred to the upper GI tract.

In the absence of prospective endoscopy-based studies, reliable data on peptic ulcer prevalence and complications are not available. Endoscopy should be reserved for patients with bleeding (see below). Medical management of dyspeptic symptoms should rely on standard treatments.

\section{Pancreatic Disease and COVID-19}

The point prevalence of SARS-CoV-2 infection presenting as acute pancreatitis is $0.27 \%$ among patients hospitalized with COVID-19. Idiopathic pancreatitis was the most common aetiology in this group (69\%) compared to $21 \%$ in patients who were COVID-19 negative. Black and Hispanic races with pancreatitis were more likely to be diagnosed with COVID-19 after multivariate analysis [72].

In a small clinical series of patients with COVID-19 pneumonia, pancreatic injury with mild clinical manifestation was detected in 9 of 52 patients (17\%). In these patients, the authors noted a higher incidence of loss of appetite and diarrhoea with increased pancreatic serum enzyme elevation, which they interpreted as pancreatic injury [73]. Pancreatic serum enzyme elevations need to be interpreted with caution. In the absence of severe abdominal pain, such findings cannot be attributed to pancreatic injury and pancreatitis, without further appropriate investigations. Conversely, it is not possible to exclude minor, subclinical cellular or vascular damage which is not detectable by radiological imaging. Further explanations for elevated pancreatic enzyme measurements in serum may result from an imbalance between production and degradation of amylase and lipase or an increased absorption of these macromolecular enzymes by a leaky gut [74].

Among postulated mechanisms responsible for the induction of mild pancreatic injury, a direct cytotoxic viral involvement is possible since the expression of ACE 2 receptors in the pancreas, and particularly in pancreatic islets, has previously been described in the context of SARSCoV-2 infection $[13,71,75]$. The TMPRSS2 and ACE 2 receptor, which together facilitate cell entry of the virus, were found on pancreatic ductular cells but causality is unproven [71]. Secondary pancreatic enzyme abnormalities as a non-specific consequence to the severe illness and drugs prescribed to treat it may sound more plausible. Reports, first from Wuhan [73] and more recently from the USA $[76,77]$ have reported cases in young people who were either overweight or obese with atypical, acute but proven pancreatitis in the context of a SARS-CoV-2 infection. The pattern of pancreatic inflammation was unusual with mild pancreatic oedema but without peripancreatic necrosis, and with distinct duodenal/periduodenal inflammation accompanied by a profound systemic inflammatory response [76, 77]. The largest case series of clinical outcomes was reported from the USA [78]. There were 339 patients with acute pancreatitis managed between March and June 2020, 75 (22\%) of whom were PCR positive for SARS-CoV-2, 14 (18.7\%) tested positive for COVID-19. There were no significant differences between infected patients and those not infected with respect to age, gender, ethnicity or body mass index. Those who were COVID-19 positive had a higher Charlson Comorbidity Index, and Bedside Index of Severity in Acute Pancreatitis scores were significantly higher in the COVID-19-positive patients. Alcoholic and idiopathic acute pancreatitis were predominant in the non-infected patients and significantly different from the COVID-19 cohort, and mortality was significantly higher in those with existing COVID-19 who displayed more multi-organ and persistent organ failure. There were no significant differences in the pattern of acute pancreatitis between the cohorts. Thus, it seems most probable that COVID-19-associated acute pancreatitis is more frequently related to the severe systemic disease and multi-organ complications rather than directly by the virus.

It is noteworthy that camostate mesylate, a serine protease inhibitor used for the treatment of pancreatitis in Japan, is active against TMPRSS2 and inhibits SARSCoV-2 infection in human lung cells and is currently being evaluated in clinical trials [13]. On the other hand, hydroxychloroquine promoted for treatment of COVID-19 has been shown to induce pancreatitis in experimental settings [79].

\section{GI Emergencies in COVID-19 Patients}

GI emergencies during the COVID-19 pandemic represent a challenge in clinical practice. Diarrhoea is the most common GI symptom associated with COVID-19, 
but it is usually mild. However, some patients report severe diarrhoea with electrolyte disturbances or bloody, inflammatory diarrhoea during or before onset of pulmonary symptoms $[80,81]$.

Patients with severe COVID-19 were more likely to have gastrointestinal symptoms, especially abdominal pain $[82,83]$, which often requires emergency consultation. Among the differing causes, some cases of acute pancreatitis have been reported to be primarily induced by the SARS-CoV-2 virus $[74,75,78]$ (see above). There are several reports of acute cholecystitis. One recent report provides well-documented presentations of two COVID-19 patients with acute acalculous cholecystitis, both presenting before the overt appearance of COVID-19 disease [84]. Radiological evidence supported by post-mortem evidence in one of the cases indicates the involvement of the gallbladder and biliary tract in the SARS-CoV-2 infection. This might be expected since gallbladder epithelial cells and bile duct cells express ACE 2 and could thus be a target for the virus.

GI bleeding is one of the most frequent reasons for emergency consultation. During the pandemic outbreak of SARS-CoV-2 virus, GI bleeding requiring the presence of a GI specialist can occur in patients suffering from COVID-19, but also in patients not suffering from this infection. GI bleeding in patients with COVID-19 is not as frequent as other GI symptoms. A recent review article of 2,023 cases with COVID-19 [85] reported the presence of GI bleeding in 2 out of 15 studies, with a frequency of $4 \%$ in one study of 52 critically ill patients [86] and of $13.7 \%$ in another with 73 hospitalized patients [14]. Other isolated cases or case series have also been reported, usually in patients with respiratory symptoms or pneumonia, but also as the first symptom of the disease [86-91]. The cause of the bleeding is often not identified, since endoscopic procedures are not always performed, and patients are managed conservatively with high-dose PPIs [92]. When an upper GI endoscopy was performed, GI mucosal herpetic-like erosions and ulcers with biopsies testing positive for the SARS-CoV-2 virus have been reported [93]. In 24 upper GI endoscopic procedures performed in patients with COVID-19 in one study, $75 \%$ had lesions including oesophagitis (20.8\%), duodenal ulcer (20.8\%), erosive gastritis (16.6\%), neoplasm (8.3\%) and MalloryWeiss tear (4.1\%), but no data on the indication for performing the endoscopic procedures were given [93].

Lower GI bleeding may also require emergency consultation and is being reported in association with COVID-19. One study, from Italy, showed a high proportion of lesions in patients with COVID-19 who under- went colonoscopy (the reason for the procedure was not specified), including segmental colitis associated with diverticulosis $(25 \%)$, haemorrhagic ulcerative colitis (5\%) and ischaemic colitis (20\%) [93]. An ischaemic cause of GI bleeding in COVID-19 patients was confirmed in other case reports attributed to SARS-CoV-2 infection, after other aetiologies for haemorrhagic colitis had been excluded [94]. The ischaemic aetiology of these bleeding lesions has been attributed to a thrombotic dysfunction, due to excessive inflammation, a hypoperfusion state or even a direct inflammatory effect on the GI mucosa [95]. The increased levels of D-dimer and fibrinogen found in many patients with COVID-19 may underlie not only the frequent peripheral and pulmonary thrombosis, but of the intestinal hypercoagulable state leading to ischaemic events [96-98].

It would be of particular interest to analyse the incidence of stress ulcer and GI bleeding in critically ill patients on mechanical ventilation, which has been frequently needed in severe cases of COVID-19. However, contrary to expectation, to date very few data are available, and no studies have focussed on this expected complication. In one series of 73 Chinese patients, a single patient with severe respiratory distress treated with venovenous extracorporeal membrane oxygenation, had coffee ground aspirate from the nasogastric tube and a positive faecal occult blood test, but no mucosal damage was identified [14]. In another study of GI bleeding cases (melena and or haematemesis) with COVID-19, 1 of 6 patients with pneumonia and severe respiratory distress and with an endotracheal tube had bleeding, but endoscopy was not performed in any of the 6 cases, and the patients responded within $24 \mathrm{~h}$ to conservative measures [91, 99]. The paucity of data about potential bleeding linked to stress ulcers in patients during mechanical ventilation with COVID-19 may result from several reasons, the most relevant being that endoscopic procedures are not performed or are avoided where the benefit-risk ratio is debatable. Another reason is that the actual occurrence of stress-related mucosal bleeding is very low and, perhaps, counterbalanced by the increased hypercoagulability state found in these patients [96]. It might also be due to both factors acting together with the current widespread use of intravenous PPIs in ICUs. As a prophylactic therapeutic measure, PPI treatment is more effective than $\mathrm{H}_{2} \mathrm{RA}$ in the prevention of stress ulcer and upper GI bleeding with a similar risk of nosocomial pneumonia [99].

Conversely, other common GI emergencies not linked to the SARS-CoV-2 virus still can occur during the pandemic. This also represents a challenge in clinical prac- 
Table 1. Scheme to prioritize gastrointestinal procedures based on medical urgency and risk of procedural risk and COVID-19 in patients

\begin{tabular}{llll}
\hline & & Medical emergency & High $^{3}$ \\
\cline { 3 - 4 } $\begin{array}{l}\text { Covid-19 and } \\
\text { procedure risk }\end{array}$ & $\begin{array}{l}\text { Low risk } \\
\text { Patients: } \\
\text { negative testing; no symptoms; no close contact } \\
\text { with COVID-19 patients }\end{array}$ & $\begin{array}{l}\text { Consider non-procedural care } \\
\text { if available, and evaluate the } \\
\text { potential consequences for long } \\
\text { Procedure: } \\
\text { not aerosol generating }{ }^{2}\end{array}$ & $\begin{array}{l}\text { Proceed with the } \\
\text { appropriate procedure for } \\
\text { the medical urgency } \\
\text { procedures }\end{array}$ \\
& $\begin{array}{l}\text { High risk } \\
\text { Patients: } \\
\text { positive testing; suspected symptoms; close contact } \\
\text { with COVID-19 patients } \\
\begin{array}{l}\text { Procedure: } \\
\text { aerosol generating }\end{array}\end{array}$ & $\begin{array}{l}\text { Shared decision-making to } \\
\text { consider non-procedure care }\end{array}$ & $\begin{array}{l}\text { Optimize pre-procedure } \\
\text { health based on } \\
\text { potentially modifiable risk } \\
\text { factors known to improve } \\
\text { outcomes while awaiting } \\
\text { procedure date }\end{array}$ \\
\end{tabular}

\footnotetext{
${ }^{1}$ Endoscopic aerosol-generating procedures include all upper gastrointestinal (GI) tract procedures. ${ }^{2}$ Low medical urgency includes all screening and surveillance procedures, as well as diagnostic and treatment procedures of suspected benign diseases. ${ }^{3}$ High medical urgency includes severe GI bleeding, cholangitis due to common bile duct stones, malignant upper GI or colonic occlusion, high suspicion of malignant disease and all urgent surgical procedures. Individual evaluation needed. Modified from Rouillard et al. [102].
}

tice, not only because patients and health professionals are at high risk of acquiring the infection in hospitals which are mostly dedicated to treating COVID-19, but because most GI services have dramatically reduced the number of procedures to contain the spread of the disease. Several studies have reported a sharp decrease in the number of GI emergency endoscopic procedures, both linked to a reduction in the number of patients requiring medical attention and a reduction in the number of procedures performed in patients with GI emergencies. In Austria there was a 55\% decline in non-variceal upper GI bleeding events, although there was no change in variceal bleeding [100]. In a study from New York, USA, patients with GI bleeding admitted during the pandemic had more severe events and poorer outcomes compared to those admitted prior to the pandemic [101]. When the analysis was performed excluding patients with COVID-19, the association still persisted suggesting that these data reflect the patients' reluctance to be referred to hospital during the pandemic, and/or a higher threshold for hospital admission [101]. Alternatively, in order to reduce, mitigate and control the COVID-19 pandemic and optimize resources, health care systems and GI units in particular have restructured their daily operations and activity. This has obligated medical teams to define which procedures could be deferred or performed based on their medical urgency taking account of the COVID-19 and procedural risks of spreading the disease and the expected outcomes for the patient. These procedures include diagnostic or therapeutic upper and lower endoscopy, their indication and the availability of appropriate personal protection equipment. Table 1 suggests a modified proposal from that issued by the Kaiser Permanente in Northern California that can serve as reference for other institutions [102]. Further helpful directions have been suggested by an international group of experts [103]. They looked at the impact of COVID-19 on GI services and the implications for patients who do not have COVID-19 but do have GI problems during the pandemic. They identified three phases of the disease, the acute phase, the adaptation phase and the consolidation phase, and provide useful proposals to organize the approach to maximize the effectiveness of services and to mitigate risks for GI patients during this new era of COVID-19.

\section{Endoscopic and Other GI Interventions in COVID-19 Patients}

The large number of COVID-19 cases has led to radical changes in endoscopy services as clinicians have tried to continue offering patients what are often life-saving services during this airborne viral pandemic. This has led to necessary reductions in unit throughput to maintain the 
safety of patients and staff, with activity in the UK dropping to $5 \%$ of normal at the pandemic peak, and internationally a reduction of $85 \%$ was reported $[104,105]$. This has led to a backlog of cases leading to real concern about cancer progression and delayed diagnoses with an equal or greater impact on mortality than the COVID-19 pandemic, with an estimated 6,280 additional cancer deaths overall in England and over 33,890 in the USA [106].

Upper GI endoscopy procedures with open suctioning, including endoscopic retrograde cholangiopancreatography, endoscopic ultrasound and transnasal endoscopy, are considered aerosol-generating procedures (AGPs) [107]. The virus-carrying aerosols are not well blocked by the use of standard surgical masks, and all guidelines currently recommend the use of level 2 personal protective equipment (PPE) for such procedures including FFP3 masks, visors, head coverings, long-sleeved fluid-resistant gowns, two pairs of gloves and shoe coverings or cleanable shoes [108-111]. It is time consuming to put on, "don," and remove, "doff," the latter being especially critical to do in the correct safe sequence to avoid infection from the PPE itself. It is also hot and unpleasant to work in PPE, and it severely impedes communication between team members, with sessions usually lasting for a maximum $2-3 \mathrm{~h}$. The number of patients that can be endoscoped on a single list is estimated to be reduced by $50 \%$ in level 2 PPE [112-114]. Nevertheless, when applied properly, level $2 \mathrm{PPE}$ appears effective in keeping staff and patients safe [115]. Upper GI physiological investigations requiring nasal intubation (oesophageal manometry, impedance/pH studies, small bowel manometry etc.) are also considered AGPs and require level 2 PPE, but lower GI physiological studies are not [116]. Breath tests undertaken by GI labs including hydrogen methane breath tests, ${ }^{13} \mathrm{C}$ urea breath tests, etc. could be considered AGPs; however, many of these can be administered by post in the home environment.

Lower GI endoscopy may also be aerosol generating, but different groups have viewed this risk differently. Viral RNA is detectable in stool and has been detected even in sewage plants, but it is unclear whether this translates into viable virus. There is some evidence that colonic fluid rapidly inactivates viral particles, and early small studies did not detect viable virus [117-119]; however, one study looking at those with a detectable viral RNA stool load did isolate viable virus in 2 of 3 patients [113]. Therefore, lower GI endoscopy may have a substantially lower risk of passing on infection, and some societies and guideline groups, but not all, have recommended lower levels of PPE (level 1: surgical mask, visor, head covering, long- sleeved apron, one set of gloves) on this basis if patients have had negative nasopharyngeal PCR swabs for COVID-19 [13, 120]. This allows closer to normal room throughput, at $70-80 \%$ of normal. CT colonography is not considered an AGP, but level 1 PPE (as above) is recommended [121].

The BSG has recently recommended that with telephone triage and swabbing pre-procedure in low prevalence areas, all endoscopy (including upper GI AGPs) are acceptable in level 1 PPE [122]. This is in part on the basis that in a recent multi-centre study of 6,200 patients who had all had telephone triage and half had PCR swab testing, where no patient or member of endoscopy staff was shown to have contracted COVID-19 within 14 days of their procedure [123]. However, this is not universally accepted with international variation here. Endoscopy units also need to adapt to the pandemic, with the development of "cold" or "COVID-minimized" facilities being recommended which actively seek to exclude COVID-19 by telephone triage of all patients 5-7 days before appointment and nasopharyngeal PCR swabs $48-72 \mathrm{~h}$ before the procedure [114]. Units need to arrange for social distancing avoiding build-ups in reception, recovery or discharge areas, ideally a linear flow through the unit to avoid patient pathways crossing and sufficient time between procedures for aerosols to settle, depending on room air exchanges, and for appropriate levels of endoscopy suite cleaning between cases. Units should separate "cold" elective work from "hot" emergency work where the patient is either known to have COVID-19 or there is insufficient time to establish COVID-19 status [114]. These requirements also contribute to the slower running of units despite level 1 PPE. In some areas which did not have a significant viral peak and still have low prevalence, far fewer measures have been required, and endoscopy has been minimally interrupted and indicates what might be achieved by a reappraisal of the services and introduction of strategies of mitigation [103].

Despite the development of COVID-19-minimized facilities, patients have been reluctant to attend hospitals for medical emergencies or in cases where they are at high risk of a serious adverse medical outcome. Patients' attitude to risk perception as a barrier to GI endoscopy has recently been published [124]. Anecdotally, in the service at the John Radcliffe Hospital, Oxford, UK, 1/3 of patients with a positive faecal immunochemical test (FIT) who have a cancer probability rate of $8-10 \%$ and were booked as part of the UK National Bowel Cancer Screening Programme, were unwilling to come for urgent colonoscopy, preferring to wait. This is very similar to the figures in an 
Italian survey of non-attendance rates for "fast-track" urgent procedures which increased as the pandemic progressed [125]. It is critical that we develop mechanisms to find a way to deliver risk messages that allow patients to make rational decisions about their optimal care at a time of high anxiety generated by the press and social media [126]. Patient concern about catching COVID-19 through attendance for endoscopy has led to some guidance documents to recommend daily symptom checks for endoscopy staff, and one off or even regular retesting in high prevalence areas $[111,122]$. If staff are infected, recent US CDC guidance has moved from a symptom and testbased strategy to confirm negativity to a time-based strategy for return to work [127]. Health care workers with mild to moderate COVID-19 may return after 10 days if fever free and symptoms are improved and not severely immunocompromised.

The backlog of cases and reduced endoscopy unit throughput expose patients to the serious risk of harm and worse outcomes due to the long waits for procedures, even if they are willing to attend. Emergency endoscopy for GI bleeding, bolus obstruction and cholangitis has largely continued, but we need to risk stratify elective patients as endoscopy services resume so that those at highest risk receive endoscopy first. This is perhaps simplest for lower GI endoscopy where quantitative FIT testing is widely and cheaply available, and with a cut-off at $10 \mathrm{ng} / \mathrm{g}$ (qFIT10) is both sensitive and specific for colorectal cancer in symptomatic patients. Use of FIT10 would allow detection of $80-90 \%$ of the cancers in a cohort with the need to urgently colonoscope only $10 \%$ of the patients $[128,129]$. Modelling suggests that use of FIT10 could salvage $90 \%$ of the life years lost due to cancer diagnosis delays [130]. Calprotectin is already established for IBD diagnosis and monitoring [131]. For upper GI endoscopy biomarkers are less well established, but there is a need to avoid doing low-yield endoscopy, for example, dyspepsia without alarm features or simple reflux responding to PPIs. It seems likely in the post-COVID-19 era that endoscopy will be increasingly driven by pre-endoscopy biomarkers with expected higher rates of advanced imaging and therapeutic procedures per case, leading to "precision endoscopy."

\section{Pharmacotherapeutic Considerations for GI Treatments in COVID-19 Patients}

Both the pharmacological and non-pharmacological managements of COVID-19 are outside the scope of this review. However, there are several comprehensive re- views [132-134] to which the reader is referred. In this final section we highlight the impact of SARS-CoV-2 infection and its treatments on the management of GI and liver diseases.

According to two systematic reviews [9, 135], the pooled prevalence of diarrhoea in patients with COVID-19 is $7.4-7.7 \%$, with a much higher figure of $18.3 \%$ in studies from outside China. Diarrhoea usually developed during hospitalization, with a minority presenting on admission. Since stool cultures for Clostridium difficile were negative in all patients and faecal leucocytes or calprotectin values not presented, diarrhoea may have been related to drug treatment(s) [135]. Some repurposed drugs against SARS-CoV-2 such as antivirals, especially lopinavir-ritonavir combinations, antimalarials and antimicrobials can induce diarrhoea, nausea and also vomiting. Since drug discontinuation is not always possible, antidiarrhoeal compounds must be given to prevent dehydration and electrolyte disturbances. However, to avoid delaying viral clearance $[9,136]$, antisecretory compounds (e.g., racecadotril) should be preferred to combination (antisecretory and antimotility) agents like loperamide.

Similarly, nausea and vomiting (pooled prevalence $4.6-7.8 \%)[5,9,66]$ need treatment to prevent dehydration and avoid interference with non-invasive ventilation, when needed. Anti-emetics should be used with caution since these drugs prolong the QTc interval [136], especially when combined with other drugs being used for COVID-19 such as chloroquine, hydroxychloroquine and azithromycin (see below).

The gut-lung axis is bidirectional, and endotoxins and microbial metabolites can impact the lung through the bloodstream and, when lung inflammation occurs, it can affect the gut microbiota [137]. Several studies show that respiratory viral infections are associated with a change in the intestinal microecology [138]. Compared with controls, COVID-19 patients show significant alterations in faecal microbiota, with enrichment of opportunistic pathogens and depletion of beneficial commensals including Lactobacilli and Bifidobacteria, on admission and during hospitalization [139-141]. Depleted symbionts and gut dysbiosis persisted even after clearance of SARSCoV-2 and resolution of respiratory symptoms [141]. Probiotics with anti-inflammatory effects could be useful to restore the intestinal microecology and prevent secondary bacterial infection in patients with COVID-19 [142-144]. However, not all probiotics are alike. Although probiotics shorten the duration of acute respiratory infections [145] and reduce the rate of ventilatorassociated pneumonia in critically ill patients on mechan- 
ical ventilation [144, 145], blind use of conventional probiotics for COVID-19 is not recommended until results of well-designed clinical trials with specific probiotic formulations are available [146].

Due to stool viral shedding [66] the potential risk of transmission of SARS-CoV-2 during faecal microbiota transplantation should also now be considered when planning such a procedure and selecting the donor. In endemic regions, an international panel of experts [147] recommended the RT-PCR assay in all potential donors, even when asymptomatic or having no history of highrisk travel or contacts. Alternatively, donor stools should be stored and quarantined for 30 days before use and released only if the donor has not developed symptoms.

Patients with IBD and GI cancer represent a challenge for gastroenterologists and oncologists with patients on immune-modulating treatments and biological and/or cytotoxic drugs [148]. Despite continuing current (monoor combination) therapies [17], the prevalence rate of COVID-19 [149-151] or development of severe complications in IBD patients is not increased [22, 150]. Corticosteroids and mesalazine are risk factors for severe COVID-19 among IBD patients, but this is not the case for TNF antagonists [18], such as infliximab which seems useful to treat both the underlying inflammation and SARS-CoV-2 pneumonia by countering the cytokine storm [21, 152]. The SECURE-IBD registry [153] will allow a comprehensive outcome assessment of IBD patients with concomitant COVID-19, treated with different therapies.

Cancer patients may be immunocompromised due to their underlying malignancy or anticancer therapy and carry multiple risk factors, placing them at higher risk of developing infections. Compared to the general population, the increased risk of contracting SARS-CoV-2 is estimated to be twofold [154]. For GI cancer patients, limiting the risk of infection without compromising the treatment of the cancer should be the goal. Whenever possible, surgery should be postponed during the epidemic and oral chemotherapy should be favoured [155]. When needed, radiotherapy should follow the RADS principle (remote visits, avoid radiation, defer radiation, shorten radiation) [156].

Overt GI bleeding calls for endoscopic evaluation but during the pandemic urgent procedures were often deferred [157], giving priority to aggressive medical management. For both peptic lesions (which are observed in $75 \%$ of upper GI endoscopies [85]) and upper GI bleeding, PPIs are indicated (oral or intravenously, respectively) $[92,158]$, but, taking into account the many cotreat- ments in COVID-19 patients and the fear of DDIs, compounds with little or no interaction with CYP 450 (pantoprazole or rabeprazole) should be preferred [158]. Because of the coagulopathy driven by SARS-CoV-2 infection $[96,97]$, patients are often treated with medium or high-dose anticoagulants [159]. NSAIDs and single or dual antiplatelet therapy are all risk factors for upper GI bleeding and pose additional risk when given concomitantly with anticoagulation [159]. In this setting, PPI use $[159,160]$ should follow the same precautions [158].

Concern about the use of PPIs has been raised since a population-based, online survey [161] found that, among PPI users, there was an increased risk of being infected with COVID-19. However, this study did not consider that younger patients with COVID-19 were unlikely to be respecting the shielding advised and generally adhered to by older generations. A further communication [162] suggested that PPI treatment is a significant risk factor (OR 2.37, 95\% CI 1.08-5.22) for the development of secondary infections in patients with COVID-19 and consequent development of acute respiratory distress syndrome, leading to a significantly higher index mortality. However, there is an error in the figures presented which requires further details to confirm these results. A very large (132,316 patients), Korean, nationwide cohort study with propensity score matching [163] showed that PPI use did not increase susceptibility to SARS-CoV-2 infection but was associated with worse outcomes of COVID-19.

Besides their antisecretory activity, PPIs exert different pleiotropic effects, including anti-inflammatory and immunomodulating effects [164], with some studies showing antiviral activity, and one [165] revealing inhibition of SARS-CoV-2 replication. In addition, PPIs affect vacuolar ATPase pumps leading to raised endolysosomal $\mathrm{pH}$ and targeting endosomal complexes, crucial for viral transport [for a review, see 166]. Taken together, it has been suggested that PPIs could have a therapeutic role in the treatment of COVID-19 [166, 167]. Some preliminary evidence of PPI benefits in the prevention of viral infections exists from a randomized trial where lansoprazole was associated with a reduction of frequency of the common cold and COPD exacerbation, thus attenuating the chance of contracting a viral infection [168]. In a retrospective case-control study of 179 elderly patients, those on a PPI were 2.3 times less likely (OR $0.44,95 \%$ CI $0.23-$ 0.81 ) to be infected by SARS-CoV-2 and develop COVID-19 when compared to those not taking a PPI [169].

It is difficult at this time to reconcile this evidence. Although associated with a worse outcome in COVID-19 
patients, PPIs do not increase the chance of getting the infection and may actually reduce it. It is worthwhile noting that, in the report showing more co-infections in PPI users [162], almost $50 \%$ of the patients taking these drugs had no clear indication for acid suppression treatment. This further emphasizes the need for appropriateness of prescribing in the COVID-19 era.

In computer simulations, famotidine (the only currently available $\mathrm{H}_{2} \mathrm{RA}$ ) was identified as a potential inhibitor of the 3-chymotrypsin-like protease of the SARSCoV-2 [170, 171]. This finding, together with the observation of an apparent clinical benefit with famotidine in COVID-19 patients, who were taking the drug for acidrelated reflux, prompted a small study [67], which showed that high-dose oral famotidine is associated with improved self-reported outcomes in non-hospitalized patients with COVID-19. Two US observational studies [68, 172 ] with propensity score matching reported that famotidine use in hospitalized patients is associated with a lower risk of clinical deterioration, leading to intubation or death. In both studies, patients receiving famotidine displayed lower serum concentrations of inflammatory markers such as ferritin, C-reactive protein and procalcitonin. However, a study performed in Hong Kong did not find any association between the use of this $\mathrm{H}_{2} \mathrm{RA}$ and COVID-19 severity [173].

The mechanism of this proposed effect of famotidine is presently unknown, but more recent molecular docking studies have found that the binding of this $\mathrm{H}_{2} \mathrm{RA}$ to viral proteases is weak and non-specific [174]. Therefore, since COVID-19 seems to involve dysfunctional mast cell activation and histamine release [175], $\mathrm{H}_{2}$ receptor antagonism may have a role. Indeed, a recent study [176] found that combined blockade with both $\mathrm{H}_{1}$ and $\mathrm{H}_{2}$ receptors using cetirizine and famotidine, respectively, reduced intubation rate, mortality and the length of hospitalization, likely by hampering a histamine-mediated cytokine storm. While the results of the randomized clinical trial (NCT04370262) of the benefits of intravenous famotidine in treating COVID-19 are awaited, further prospective studies on both prevention and treatment with this $\mathrm{H}_{2} \mathrm{RA}$ in this challenging viral disease are needed.

Based on two systematic reviews with meta-analysis $[82,135]$, liver function tests (aspartate and alanine aminotransferases and bilirubin) were abnormal in 15-19\% of patients with COVID-19. Available evidence suggests that, in this subset of patients, liver injury can result from direct pathogenic effects by the virus, systemic inflammation with a complicated disease course or toxicity from commonly used medications [177] (see above). Indeed, liver histopathology from patients with COVID-19 shows mild lobular and portal inflammation as well as microvascular steatosis [178], findings common in drug-induced liver injury, which is more relevant in patients with hepatic disease. Symptomatic treatment with paracetamol [179] or NSAIDs [180] may well be responsible. Cautious use of antiviral agents in patients with pre-existing liver disease and DDIs should be considered. Indeed, ritonavir-boosted antiviral therapies exhibit relevant interactions through CYP34A [61]. Since abnormal liver function is associated with worse outcomes [181-184], monitoring and evaluating enzyme elevations are the standard of care in patients with COVID-19 [135].

There has been concern over the alleged risks of NSAIDs in patients affected by the SARS-CoV-2 infection. Animal studies indicate that ibuprofen upregulates the cardiac expression of ACE 2, which facilitates SARSCoV-2 entry [184]. The WHO initially recommended that ibuprofen use should be avoided for symptoms of COVID-19, but then reversed their recommendation [185], and the EMA concluded there is currently no scientific evidence establishing a link between ibuprofen and worsening of COVID-19 [186]. Cyclo-oxygenase 2 is induced by bacterial and viral infections and has complex, poorly understood roles in antipathogen immunity. In vitro studies have shown that a cyclo-oxygenase 2 selective inhibitor, given early in the infection, may enhance and/or prolong endogenous interferon responses and, thereby, increase antiviral immunity [187]. Furthermore, some NSAIDs display antiviral activity in vitro [188] and reduced mortality, length of hospitalstay and cytokine levels when combined with oseltamivir in flu patients [189].

Besides DDIs, several medications used off-label in COVID-19 cases display some cardiac toxicity, especially prolongation of the QT interval which may be associated with life-threatening arrythmias as is shown in Table 2 [190]. It is therefore mandatory to perform an ECG to measure QT/QTc and evaluate other risk factors including age, electrolyte disturbance, loop diuretic use, etc., prior to prescription, in order to quantify the risk and avoid serious cardiac complications [191]. According to one systematic review [192], only $10 \%$ of COVID-19 patients treated with chloroquine or hydroxychloroquine developed QT prolongation. In the largest reported cohort of COVID-19 patients treated to date with chloroquine/hydroxychloroquine, with or without azithromycin [193], no instances of torsade de pointes or arrhythmogenic death were reported. Although use of these medications resulted in QT prolongation, clinicians sel- 
Table 2. Potential cardiac adverse effects and drug interaction profile of COVID-19 investigational drugs

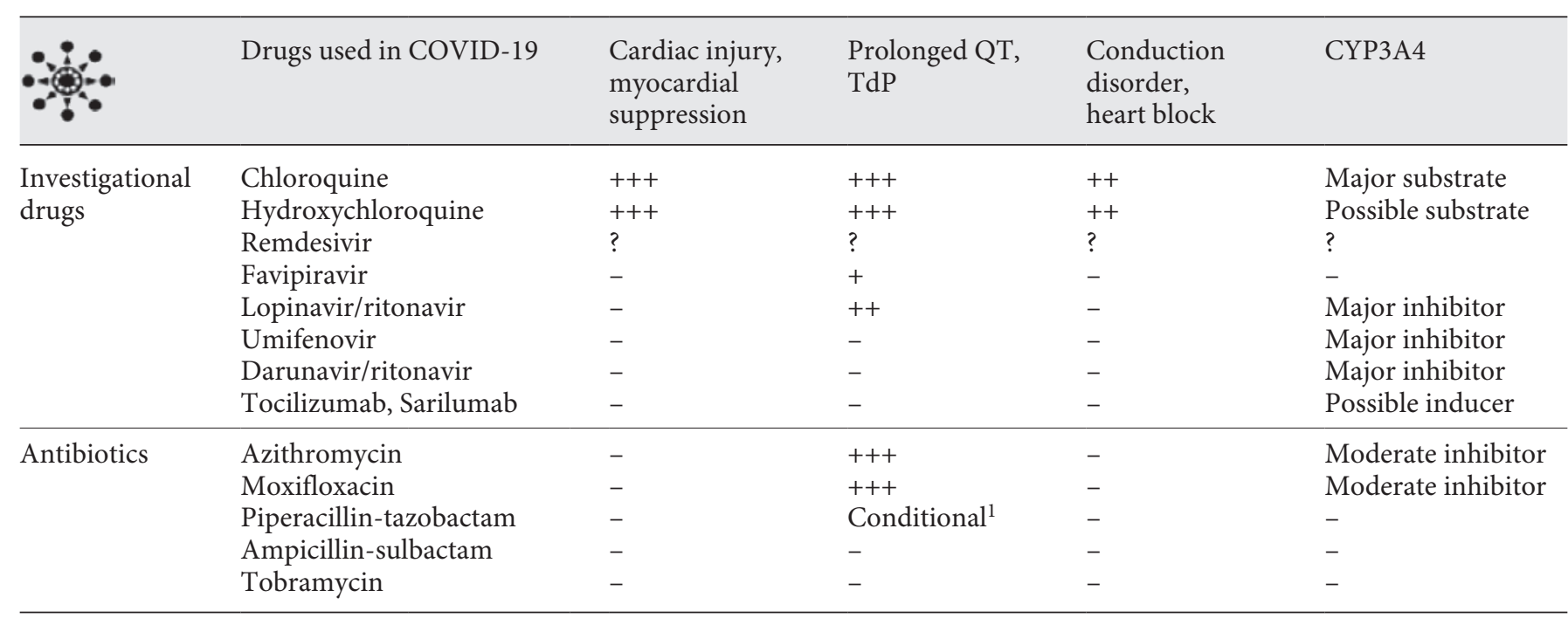

${ }^{1}$ Conditional risk for torsade de pointes (TdP) when one of these risks presents: bradycardia, hypokalaemia, hypomagnesaemia, use with concomitant QT/TdP drug, or use with drugs that can cause hypokalaemia or hypomagnesaemia. Modified from Naksuk et al [190].

dom needed to discontinue therapy. A guide for safe use of COVID-19 treatments has been published [193] and should be carefully followed.

Amongst cardiovascular drugs, those interfering with the renin-angiotensin system have been a concern in SARS-CoV-2 infection. The question of whether ACE inhibitors and angiotensin receptor blockers might worsen the prognosis of COVID-19 stems from current reports that, during treatment with these drugs, overexpression of ACE 2 receptors occurs, producing more potential docking sites for the virus $[195,196]$. This concern appears unjustified since no data show that this hypothesis translates to clinical practice. Three different studies, summarized in a thoughtful editorial [197], provide no evidence to support the hypothesis that ACE inhibitor or angiotensin receptor blocker use is associated with any risk of SARS-CoV-2 infection, the risk of severe disease in those infected or the risk of in-hospital death. A meta-analysis involving 9 studies and 3,936 patients concluded that treatment decreased mortality (OR 0.57, 95\% CI 0.38-0.84) in COVID-19 patients [198]. The European [199] and American [200] Societies of Cardiology advise that patients should not discontinue renin-angiotensin system inhibitors since periods of unstable blood pressure due to drug withdrawal or therapeutic switch are associated with excess cardiovascular risk [201].
Host defences against both bacterial and viral infections rely on an effective immune system. A varied and nutritious diet is important for the proper functioning of the immune response including anti-inflammatory and anti-oxidant foods and micronutrients [202]. Vitamin D is essential to immune function through modulation of both the adaptive and innate immune systems [203] and may perturb viral cellular infection by interacting with viral cell entry at the ACE 2 receptor.

Most but not all observational data comparing outcomes from various countries suggest an inverse link between vitamin D levels and the severity of COVID-19 outcomes, including mortality [204]. Evidence supporting the role of vitamin $\mathrm{D}$ in reducing the risk of COVID-19 includes [205]:

- the outbreak occurred in winter, a time when 25-hydroxyvitamin D concentrations are lowest;

- the number of cases in the southern hemisphere near the end of summer are low;

- vitamin D deficiency contributes to acute respiratory distress syndrome;

- case-fatality rates increase with age and with chronic disease comorbidity;

- both of which are associated with lower 25-hydroxyvitamin D concentration.

Considering these findings in the current COVID-19 pandemic, it would be wise to test for vitamin D levels, 
especially frontline health care professionals, to ensure they have adequate levels and correct any deficiency with dietary supplementation [205].

\section{Summary and Conclusions}

The SARS-CoV-2 virus may lead to significant systemic disease and involve the GI tract, liver, biliary tract and pancreas by mechanisms involving cell entry by the ACE 2 receptor and TMPRSS2, which are dysregulated. In IBD clinical studies and registry data show that age, the presence of comorbidities and active disease are associated with increased adverse outcomes. SARS-CoV-2 infection does not appear to have significant direct hepatoxicity but is associated with increased mortality in those with cirrhosis, by increasing the risks of decompensation.

Upper GI tract symptoms are frequently reported in COVID-19 patients, most frequently anorexia and nausea; however, the expression of ACE 2 receptors is significantly lower in the oesophagus and stomach than the lower intestines.

Acute pancreatitis does not appear to be causally related to SARS-CoV-2 infection although pancreatic enzyme abnormalities are not infrequent, most likely as a non-specific consequence of severe illness and the use of extensive medications, but a direct viral effect has not been excluded.

GI bleeding in patients with COVID-19 is not as frequent as might be expected, and the cause of the bleeding is often not found, because endoscopic procedures are not always performed and patients are managed conservatively. Herpetic-like lesions in the upper GI tract and ischaemic lesions attributed to a hypercoagulability syndrome and thrombotic events in the colon have been reported.

Endoscopy can be carried out safely in a COVID-19 environment with appropriate PPE and the establishment of new safe protocols for AGPs, but endoscopies are substantially slower leading to a case backlog. A decrease in the number of GI emergency endoscopic procedures has been linked to a reduction in the number of patients seeking medical attention during the pandemic as well as a reduction in the number of procedures performed because of the complexities mentioned. The risk of unknown cancer in the endoscopy case backlog can be minimized by clinical triage and the use of low cut-off FIT testing to prioritize colonoscopy cases.

The use of some medications for managing COVID-19 may be associated with GI symptoms, and others may lead to serious adverse events or DDIs. The risks of immune-modulatory therapies in patients with IBD or CLD continue to be carefully studied but withdrawal of treatment in patients in remission is not advocated in view of the real and significant risks of relapse.

With such a new infection as SARS-CoV-2, there have been many questions and we have summarized work to date (September 30, 2020). There is much research which is ongoing and questions still to be addressed to best guide clinical gastroenterologists through their daily practice.

\section{Conflict of Interest Statement}

Richard H. Hunt has been a consultant or speaker for Biocodex, Cinclus, Daewoong, Danone, Dr Reddy, Insys, Takeda. James E. East has served on the clinical advisory board for Lumendi, Boston Scientific and Paion, clinical advisory board and ownership for Satisfai Health and received speaker fees from Falk. Angel Lanas has declared no conflicts of interest. Peter Malfertheiner has been a consultant or speaker for Alfasigma, Bayer Health Care, Danone, Luvos, Mayoly-Spindler, Nordmark. Jack Satsangi has declared no conflicts of interest. Carmelo Scarpignato has served as a speaker, consultant and/or advisory board member for Alfasigma, Pfizer, Takeda, Reckitt-Benkiser and Shionogi, and has in the past received funding from Giuliani Pharmaceuticals and Pfizer. Gwilym J. Webb has received support from the European Association for the Study of the Liver for work on SARS-CoV-2 infection in liver disease via COVID-Hep.net.

\section{Funding Sources}

This project was unfunded. James East is funded by the National Institute for Health Research (NIHR), Oxford Biomedical Research Centre (BRC). The views expressed are those of the author(s) and not necessarily those of the NHS, the NIHR or the Department of Health.

\section{Author Contributions}

R.H.H.: planned, co-ordinated and edited the overall manuscript and wrote the first four sections and the summary. J.S.: wrote the IBD section. G.J.W.: wrote the liver section. P.M.: wrote the upper GI and pancreas section. A.L.: wrote the emergencies section. J.E.E.: wrote the endoscopy and GI interventions section. C.S.: wrote the treatments section. All authors contributed to various other sections and edited and agreed the final paper. 


\section{References}

1 Zhu N, Zhang D, Wang W, Li X, Yang B, Song J, et al.; China Novel Coronavirus Investigating and Research Team. A Novel Coronavirus from Patients with Pneumonia in China, 2019. N Engl J Med. 2020 Feb;382(8):727-33.

2 Johns Hopkins University COVID-19 daily dashboard [cited 2020 Oct 22]. Available from: https://coronavirus.jhu.edu/map.html

3 Chen Y, Liu Q, Guo D. Emerging coronaviruses: genome structure, replication, and pathogenesis. J Med Virol. 2020 Apr;92(4): $418-23$.

4 Docherty AB, Harrison EM, Green CA, Hardwick HE, Pius R, Norman L, et al; ISARIC4C investigators. Features of 20,133 UK patients in hospital with COVID-19 using the ISARIC WHO Clinical Characterisation Protocol: prospective observational cohort study. BMJ. 2020 May;369:m1985.

5 Han C, Duan C, Zhang S, Spiegel B, Shi H, Wang $\mathrm{W}$, et al. Digestive symptoms in COVID-19 patients with mild disease severity: clinical presentation, stool viral RNA testing, and outcomes. Am J Gastroenterol. 2020 Jun; 115(6):916-23.

6 Tong JY, Wong A, Zhu D, Fastenberg JH, Tham T. The Prevalence of Olfactory and Gustatory Dysfunction in COVID-19 Patients: A Systematic Review and Meta-analysis. Otolaryngol Head Neck Surg. 2020 Jul; 163(1):3-11.

$7 \mathrm{Wu} \mathrm{Y,} \mathrm{Xu,} \mathrm{Chen} \mathrm{Z,} \mathrm{Duan} \mathrm{J,} \mathrm{Hashimoto} \mathrm{K,}$ Yang, L, Liu C, Yang C. Brain, nervous system involvement after infection with Covid-19 and other coronaviruses. Behav Immun. https://doi.org/https://doi.org/10.1016/j. bbi.2020.03.031.

8 Netland J, Meyerholz DK, Moore S, Cassell $\mathrm{M}$, Perlman S. Severe acute respiratory syndrome coronavirus infection causes neuronal death in the absence of encephalitis in mice transgenic for human ACE2. J Virol. 2008 Aug;82(15):7264-75.

9 Parasa S, Desai M, Thoguluva Chandrasekar V, Patel HK, Kennedy KF, Roesch T, et al. Prevalence of Gastrointestinal Symptoms and Fecal Viral Shedding in Patients With Coronavirus Disease 2019: A Systematic Review and Meta-analysis. JAMA Netw Open. 2020 Jun;3(6):e2011335.

10 Zuo T, Liu Q, Zhang F, et al. Depicting SARS$\mathrm{CoV}-2$ faecal viral activity in association with gut microbiota composition in patients with COVID-19. Gut. https://doi.org/10.1136/ gutjnl-2020-322294. Epub 2020 Jul 20.

11 Tay MZ, Poh CM, Rénia L, MacAry PA, Ng LF. The trinity of COVID-19: immunity, inflammation and intervention. Nat Rev Immunol. 2020 Jun;20(6):363-74.

12 Siddiqi HK, Mehra MR. COVID-19 illness in native and immunosuppressed states: A clinical-therapeutic staging proposal. J Heart Lung Transplant. 2020 May;39(5):405-7.

13 Hoffmann M, Kleine-Weber H, Schroeder S, Krüger N, Herrler T, Erichsen S, et al. SARS-
CoV-2 Cell Entry Depends on ACE2 and TMPRSS2 and Is Blocked by a Clinically Proven Protease Inhibitor. Cell. 2020 Apr; 181(2):271-280.e8.

14 Xiao F, Tang M, Zheng X, Liu Y, Li X, Shan H. Evidence for gastrointestinal infection of SARS-CoV-2. Gastroenterology. 2020 May; 158(6):1831-1833.e3.

15 Novak JK, et al. Age, inflammation and disease location are critical determinants of intestinal expression of SARS-CoV-2 receptor ACE2 and TMPRSS2 in inflammatory bowel disease. Gastroenterology. 2020;12:S00165085(20)30653-3.

16 Kennedy NA, Jones GR, Lamb CA, Appleby R, Arnott I, Beattie RM, et al. British Society of Gastroenterology guidance for management of inflammatory bowel disease during the COVID-19 pandemic. Gut. 2020 Jun; 69(6):984-90.

17 Danese S, Cecconi M, Spinelli A. Management of IBD during the COVID-19 outbreak: resetting clinical priorities [published correction appears in Nat Rev Gastroenterol Hepatol. 2020 May 6]. Nat Rev Gastroenterol Hepatol. 2020 May;17(5):253-5

18 Brenner EJ, Ungaro RC, Gearry RB, Kaplan GG, Kissous-Hunt M, Lewis JD, Ng SC, Rahier J-F, Reinisch W, Ruemmele FR, Steinwurz F, Underwood FE, Zhang X, Colombel J-F, Kappelman MD. Corticosteroids, but not TNF antagonists, are associated with adverse COVID-19 outcomes in patients with inflammatory bowel diseases: results from an international registry. Gastroenterology. 2020; 159(2):481-91.e3.

19 Brenner EJ, Ungaro RC, Colombel JF, Kappelman MD. SECURE-IBD database public data update [cited 2020 Sep 9]. Available from: covidibd.org

20 Simon D, Tascilar K, Krönke G, et al. Patients with immune-mediated inflammatory diseases receiving cytokine inhibitors have low prevalence of SARS-CoV-2 seroconversion. Nat Commun. 2020;11(1):3774

21 Bezzio C, Saibeni S, Variola A, Allocca M, Massari A, Gerardi V, et al.; Italian Group for the Study of Inflammatory Bowel Disease (IG-IBD). Outcomes of COVID-19 in 79 patients with IBD in Italy: an IG-IBD study. Gut. 2020 Jul;69(7):1213-7.

22 Lukin DJ, Kumar A, Hajifathalian K, Sharaiha RZ, Scherl EJ, Longman RS, et al.; Jill Roberts Center Study Group Study Group; Weill Cornell Medicine-Gastrointestinal Study Group. Baseline Disease Activity and Steroid Therapy Stratify Risk of COVID-19 in Patients With Inflammatory Bowel Disease. Gastroenterology. 2020 May;S00165085(20)34738-7. https://doi.org/10.1053/j. gastro.2020.05.066.

23 Fiorino G, Allocca M, Furfaro F, et al. Inflammatory bowel disease care in the COVID-19 pandemic era: the Humanitas, Milan experience. J Crohns Colitis. 2020;jjaa058. https:// doi.org/10.1093/ecco-jcc/jjaa058. Epub 2020 Mar 24.

24 Chen J, Peng X, Zhang M, Zhi M. Impact of medication discontinuation on patients with inflammatory bowel disease during the COVID-19 outbreak. Gastroenterology. 2020 Jun;S0016-5085(20)34779-X. https://doi. org/10.1053/j.gastro.2020.05.087.

25 Brain O, Satsangi J. Therapeutic decisions in inflammatory bowel disease in the SARS-CoV-2 pandemic. Gastroenterology. S0016-5085(20)34775-2. https://doi.org/ 10.1053/j.gastro.2020.05.083.. Epub 2020 Jun 15 .

26 Magro F, Dias CC, Morato M. Aminosalicylates and COVID-19: facts or Coincidences? Gastroenterology. 2020 Jun;S0016-5085(20) 34785-5. https://doi.org/10.1053/j.gastro. 2020.05.092.

27 Bangma A, Voskuil MD, Weersma RK. TNFa-antagonist use and mucosal inflammation are associated with increased intestinal expression of SARS-CoV-2 host protease TMPRSS2 in patients with inflammatory bowel disease. Gastroenterology. 2020 Jun;S0016-5085(20)34783-1. https://doi. org/10.1053/j.gastro.2020.05.091.

28 Siau K, Iacucci M, Dunckley P, Penman I. The impact of COVID-19 on gastrointestinal endoscopy training in the United Kingdom. Gastroenterology. 2020; https:// doi.org/ 10.1053/j.gastro.2020.06.015.

29 Walsh A, Matini L, Hinds C, Sexton V, Brain $\mathrm{O}$, Keshav S, et al. Real-time data monitoring for ulcerative colitis: patient perception and qualitative analysis. Intest Res. 2019 Jul;17(3): 365-74.

30 Cai Q, Huang D, Yu H, et al. COVID-19: abnormal liver function tests. J Hepatol. 2020;S0168-8278(20)30218-X. https://doi. org/10.1016/j.jhep.2020.04.006. Epub 2020 Apr 13.

31 Phipps MM, Barraza LH, LaSota ED, Sobieszczyk ME, Pereira MR, Zheng EX, et al. Acute Liver Injury in COVID-19: Prevalence and Association with Clinical Outcomes in a Large US Cohort [published online ahead of print, 2020 May 30]. Hepatology. 2020 May; 72(3):807-17.

32 Wang Y, Liu S, Liu H, et al. SARS-CoV-2 infection of the liver directly contributes to hepatic impairment in patients with COVID-19. J Hepatol. 2020;S0168-8278(20)30294-4. https://doi. org/10.1016/j.jhep.2020.05.002. Epub 2020 May 10.

33 Puelles VG, Lütgehetmann M, Lindenmeyer MT, et al. Multiorgan and renal tropism of SARS-CoV-2. N Engl J Med. 2020 Aug; 383(6):590-2.

34 Wichmann D, Sperhake JP, Lütgehetmann M, Steurer S, Edler C, Heinemann A, et al. Autopsy findings and venous thromboembolism in patients with COVID-19: a prospective cohort study. Ann Intern Med. 2020 Aug; 173(4):268-77. 
35 Tian S, Xiong Y, Liu H, Niu L, Guo J, Liao M, et al. Pathological study of the 2019 novel coronavirus disease (COVID-19) through postmortem core biopsies. Mod Pathol. 2020 Jun;33(6):1007-14.

36 Bangash MN, Patel JM, Parekh D, et al. SARS $\mathrm{CoV}-2$ : is the liver merely a bystander to severe disease? J Hepatol. 2020;S01688278(20)30355-X. https://doi.org/10.1016/j. jhep.2020.05.035. Epub 2020 Jun 2.

37 Chai X, Hu L, Zhang Y, Han W, Lu Z, Ke A, et al. Specific ACE2 Expression in Cholangiocytes May Cause Liver Damage After 2019 . nCoV Infection: bioRxiv 2020.02.03.931766; doi:https://doi.org/https://doi.org/10.1101/ 2020.02.03.931766

38 Zou X, Chen K, Zou J, Han P, Hao J, Han Z. Single-cell RNA-seq data analysis on the receptor ACE2 expression reveals the potential risk of different human organs vulnerable to 2019-nCoV infection. Front Med. 2020 Apr; 14(2):185-92.

39 Zhang C, Shi L, Wang FS. Liver injury in COVID-19: management and challenges. Lancet Gastroenterol Hepatol. 2020 May; 5(5):428-30.

40 Iavarone M, D'Ambrosio R, Soria A, et al. High rates of 30-day mortality in patients with cirrhosis and COVID-19. J Hepatol. 2020;S0168-8278(20)30365-2. https://doi org/10.1016/j.jhep.2020.06.001. Epub 2020 Jun 8.

41 Moon AM, Webb GJ, Aloman C, et al. High mortality rates for SARS-CoV-2 infection in patients with pre-existing chronic liver disease and cirrhosis: preliminary results from an international registry. J Hepatol. 2020;S0168-8278(20)30305-6. https://doi. org/10.1016/j.jhep.2020.05.013. Epub 2020 May 21.

42 Marjot T, Moon AM, Cook JA, Abd-Elsalam S, Aloman C, Armstrong MJ, et al. Outcomes following SARS-CoV-2 infection in patients with chronic liver disease: an international registry study. J Hepatol. 2020 Oct;S01688278(20)33667-9. https://doi.org/10.1016/j. jhep.2020.09.024.

43 Williamson E, Walker AJ, Bhaskaran KJ, Bacon S, Bates C, Morton CE, et al. OpenSAFELY: factors associated with COVID-19-related hospital death in the linked electronic health records of 17 million adult NHS patients. medRxiv 2020.05.06.20092999; doi: https://doi.org/https://doi.org/10.1101/2020. 05.06.20092999.

44 Zheng KI, Gao F, Wang XB, Sun QF, Pan KH, Wang TY, et al. Letter to the editor: obesity as a risk factor for greater severity of COVID-19 in patients with metabolic associated fatty liver disease. Metabolism. 2020;108:154244.

45 Scaglione S, Kliethermes S, Cao G, Shoham D, Durazo R, Luke A, et al. The Epidemiology of Cirrhosis in the United States: A Populationbased Study. J Clin Gastroenterol. 2015 Sep; 49(8):690-6.

46 Boettler T, Newsome PN, Mondelli MU, Maticic M, Cordero E, Cornberg M, et al. Care of patients with liver disease during the COV ID-19 pandemic: EASL-ESCMID position paper. JHEP Rep. 2020 Jun;2(3):100113.

47 APASL Covid-19 Task Force, Lau G, Sharma M. Clinical practice guidance for hepatology and liver transplant providers during the $\mathrm{CO}$ VID-19 pandemic: APASL expert panel consensus recommendations. Hepatol Int. Epub 2020 May 23.

48 Boettler T, Marjot T, Newsome PN, Mondelli MU, Maticic M, Cordero E, et al. Impact of COVID-19 on the care of patients with liver disease: EASL-ESCMID position paper after 6 months of the pandemic. JHEP Rep. 2020 Oct; 2(5):100169.

49 Blach S, Kondili LA, Aghemo A, Cai Z, Dugan E, Estes C, et al. Impact of COVID-19 on global hepatitis $\mathrm{C}$ elimination efforts. J Hepatol. 2020 Aug;S0168-8278(20)30523-7. https:// doi.org/10.1016/j.jhep.2020.07.042.

50 Lleo A, Invernizzi P, Lohse AW, Aghemo A, Carbone M. Management of patients with autoimmune liver disease during COVID-19 pandemic. J Hepatol. 2020;S0168-8278(20) 30212-9. https://doi.org/10.1016/j.jhep.2020. 04.002. Epub 2020 Apr 10.

51 Tapper EB, Asrani SK. The COVID-19 pandemic will have a long-lasting impact on the quality of cirrhosis care. J Hepatol. 2020;S0168-8278(20)30217-8. https://doi. org/10.1016/j.jhep.2020.04.005. Epub 2020 Apr 13.

52 Pawlotsky JM. COVID-19 and the liver-related deaths to come [published online ahead of print, 2020 Jun 11]. Nat Rev Gastroenterol Hepatol. 2020 Sep;17(9):523-5.

$53 \mathrm{Da}$ BL, Im GY, Schiano TD. COVID-19 Hangover: A Rising Tide of Alcohol Use Disorder and Alcohol-Associated Liver Disease [published online ahead of print, 2020 May 5]. Hepatology. 2020 May;72(3):1102-8.

54 Lembach H, Hann A, McKay SC, et al. Resuming liver transplantation amid the COVID-19 pandemic. Lancet Gastroenterol Hepatol. 2020;S2468-1253(20)30187-4. https://doi. org/10.1016/S2468-1253(20)30187-4. Epub 2020 Jun 11.

55 Grein J, Ohmagari N, Shin D, Diaz G, Asperges E, Castagna A, et al. Compassionate Use of Remdesivir for Patients with Severe Covid-19. N Engl J Med. 2020 Jun;382(24):232736.

56 Wang Y, Zhang D, Du G, Du R, Zhao J, Jin Y, et al. Remdesivir in adults with severe COVID-19: a randomised, double-blind, placebocontrolled, multicentre trial. Lancet. 2020 May;395(10236):1569-78.

57 Horby P, Lim WS, Emberson JR, Mafham M, Bell JL, Linsell L, et al.; RECOVERY Collaborative Group. Dexamethasone in Hospitalized Patients with Covid-19 - Preliminary Report. N Engl J Med. 2020 Jul.

58 Reddy KR, Beavers KL, Hammond SP, Lim JK, Falck-Ytter YT; American Gastroenterological Association Institute. American Gastroenterological Association Institute guideline on the prevention and treatment of hepatitis B virus reactivation during immunosuppressive drug therapy. Gastroenterology. 2015 Jan; 148(1):215-9.

59 Webb GJ, Marjot T, Cook JA, Aloman C, Armstrong MJ, Brenner EJ, et al. Outcomes following SARS-CoV-2 infection in liver transplant recipients: an international registry study. Lancet Gastroenterol Hepatol. 2020 Aug;S2468-1253(20)30271-5. https://doi. org/10.1016/S2468-1253(20)30271-5.

60 Colmenero J, Rodríguez-Perálvarez M, Salcedo M, Arias-Milla A, Muñoz-Serrano A Graus J, et al. Epidemiological pattern, incidence and outcomes of COVID-19 in liver transplant patients. J Hepatol. 2020 Aug;S0168-8278(20)30521-3. https://doi. org/10.1016/j.jhep.2020.07.040.

61 Garrison KL, German P, Mogalian E, Mathias A. The Drug-Drug Interaction Potential of Antiviral Agents for the Treatment of Chronic Hepatitis C Infection. Drug Metab Dispos. 2018 Aug;46(8):1212-25.

62 Alqahtani SA, Schattenberg JM. Liver injury in COVID-19: the current evidence. United European Gastroenterol J. 2020 Jun;8(5):509-19.

63 Barry A, Apisarnthanarax S, O'Kane GM, Sapisochin G, Beecroft R, Salem R, et al. Management of primary hepatic malignancies during the COVID-19 pandemic: recommendations for risk mitigation from a multidisciplinary perspective. Lancet Gastroenterol Hepatol. 2020 Aug;5(8):765-75.

64 Jin X, Lian JS, Hu JH, Gao J, Zheng L, Zhang YM, et al. Epidemiological, clinical and virological characteristics of 74 cases of coronavirus-infected disease 2019 (COVID-19) with gastrointestinal symptoms. Gut. 2020 Jun; 69(6):1002-9.

65 Pan L, Mu M, Yang P, et al. Clinical characteristics of COVID-19 patients with digestive symptoms in Hubei, China: a descriptive cross-sectional multicenter study. Am J Gastroenterol. 2020 May;115(5):766-73.

66 Cheung KS, Ivan FN. Hung, MD, et al Gastrointestinal manifestations of SARS-CoV-2 infection and virus load in fecal samples from a Hong Kong cohort: systematic review and meta-analysis. Gastroenterology. $2020 \mathrm{Jul}$ 159(1):81-95.

67 Janowitz T, Gablenz E, Pattinson D, et al. Famotidine use and quantitative symptom tracking for Covid-19 in non-hospitalised patients: a case series. Gut. 2020;gutjnl-2020321852. Epub 2020 Jun 4.

68 Freedberg DE, Conigliaro J, Wang TC, et al. Famotidine use is associated with improved clinical outcomes in hospitalized COVID-19 patients: a propensity score matched retrospective cohort study. Gastroenterology. 2020;S0016-5085(20)34706-5. https://doi. org/10.1053/j.gastro.2020.05.053. Epub 2020 May 22.

69 Levinson R, Elbaz M, Ben-Ami R, Shasha D, Levinson T, Choshen G, et al. Time course of anosmia and dysgeusia in patients with mild SARS-CoV-2 infection. Infect Dis (Lond). 2020 Aug;52(8):600-2. 
70 Zhang H, Kang Z, Gong H, Xu D, Wang J, Li $Z$, et al. Digestive system is a potential route of COVID-19: an analysis of single-cell coexpression pattern of key proteins in viral entry process. Gut. 2020;69(6):1010-8.

71 Muus C, Luecken MD, Eraslan G, et al. Integrated analyses of single-cell atlases reveal age, gender, and smoking status associations with cell type-specific expression of mediators of SARS-CoV-2 viral entry and highlights inflammatory programs in putative target cells. bioRxiv 2020: 2020.04.19.049254. Available at: http:// biorxiv.org/content/early/2020/04/21/ 2020.04.19.049254 https://doi.org/10.1101/ 2020.04.19.049254.

72 Inamdar S, Benias PC, Liu Y, et al. Prevalence, risk factors, and outcomes of hospitalized patients with COVID-19 presenting as acute pancreatitis. Gastroenterology. 2020;S00165085(20)35115-5. https://doi.org/10.1053/j. gastro.2020.08.044. Epub 2020 Aug 26.

73 Wang F, Wang H, Fan J, et al. Pancreatic injury patterns in patients with COVID-19 pneumonia [cited 2020 Apr 26]. Gastroenterology 2020. Available at: https://www.sciencedirect.com/science/article/pii/ S0016508520304091?via\%3Dihub

74 Tositti G, Fabris P, Barnes E, Furlan F, Franzetti M, Stecca C, et al. Pancreatic hyperamylasemia during acute gastroenteritis: incidence and clinical relevance. BMC Infect Dis. 2001;1(1):18.

75 Yang L, Han Y, Nilsson-Payant BE, Gupta V, Wang P, Duan X, et al. A Human Pluripotent Stem Cell-based Platform to Study SARSCoV-2 Tropism and Model Virus Infection in Human Cells and Organoids. Cell Stem Cell. $2020 \mathrm{Jul} ; 27(1): 125-136 . e 7$.

76 Aloysius MM, Thatti A, Gupta A, Sharma N, Bansal P, Goyal H. COVID-19 presenting as acute pancreatitis. Pancreatology. 2020;S1424-3903(20)30154-X. https://doi. org/10.1016/j.pan.2020.05.003. Epub 2020 May 8.

77 Szatmary P, Arora A, Raraty MGT, Dunne DFJ, Baron RD, Halloran CM. Emerging phenotype of SARS-CoV2 associated pancreatitis. Gastroenterology. 2020;S0016-5085(20) 34741-7. https://doi.org/10.1053/j.gastro. 2020.05.069. Epub 2020 Jun 1.

78 Dirweesh A, Li Y, Trikudanathan G, et al. Clinical outcomes of acute pancreatitis in patients with COVID-19. Gastroenterology. 2020. https://doi.org/10.1053/j.gastro.2020. 07.038 .

79 Lerch MM, Saluja AK, Dawra R, Saluja M, Steer ML. The effect of chloroquine administration on two experimental models of acute pancreatitis. Gastroenterology. 1993 Jun; 104(6):1768-79.

80 Carvalho A, Alqusairi R, Adams A, Paul M, Kothari N, Peters S, et al. SARS-CoV-2 Gastrointestinal Infection Causing Hemorrhagic Colitis: Implications for Detection and Transmission of COVID-19 Disease. Am J Gastroenterol. 2020 Jun;115(6):942-6.
81 Ferrey AJ, Choi G, Hanna RM, Chang Y, Tantisattamo E, Ivaturi K, et al. A Case of Novel Coronavirus Disease 19 in a Chronic Hemodialysis Patient Presenting with Gastroenteritis and Developing Severe Pulmonary Disease. Am J Nephrol. 2020;51(5):33742.

82 Mao R, Qiu Y, He JS, Tan JY, Li XH, Liang J, et al. Manifestations and prognosis of gastrointestinal and liver involvement in patients with COVID-19: a systematic review and meta-analysis [published correction appears in Lancet Gastroenterol Hepatol. 2020 Jul; 5(7):e6]. Lancet Gastroenterol Hepatol. 2020 Jul;5(7):667-78.

83 Suresh Kumar VC, Mukherjee S, Harne PS, Subedi A, Ganapathy MK, Patthipati VS, et al. Novelty in the gut: a systematic review and meta-analysis of the gastrointestinal manifestations of COVID-19. BMJ Open Gastroenterol. 2020 May;7(1):e000417.

84 Balaphas A, Gkoufa K, Meyer J, Peloso A, Bornand A, McKee TA, Toso C, Popeskou SG. Covid-19 can mimic acute cholecystitis and is associated with the presence of viral RNA in the gallbladder wall. J Hepatol. 2020 Sep 2;S0168-8278(20)30550-X. https://doi. org/10.1016/j.jhep.2020.08.020.. Epub.

85 Tian Y, Rong L, Nian W, He Y. Review article: gastrointestinal features in COVID-19 and the possibility of faecal transmission. Aliment Pharmacol Ther. 2020 May;51(9):843-51.

86 Yang X, Yu Y, Xu J. et al Clinical course and outcomes of critically ill patients with SARSCoV-2 pneumonia in Wuhan, China: a single-centered, retrospective, observational study. Lancet Respir Med. 2020;8(5):475-81.

87 Lin L, Jiang X, Zhang Z, Huang S, Zhang Z, Fang Z, et al. Gastrointestinal symptoms of 95 cases with SARS-CoV-2 infection. Gut. 2020 Jun;69(6):997-1001.

88 Gadiparthi C, Perisetti A, Sayana H, Tharian B, Inamdar S, Korman A. Gastrointestinal Bleeding in Patients with Severe SARS-CoV-2 [published online ahead of print, 2020 Jun 4]. Am J Gastroenterol. 2020 Aug;115(8):12835.

89 Liang WH, Guan WJ, Li CC, et al. Clinical characteristics and outcomes of hospitalised patients with COVID-19 treated in Hubei (epicentre) and outside Hubei (non-epicentre): a nationwide analysis of China. Eur Respir J. 2020;55(6):2000562.

90 Cavaliere K, Levine C, Wander P, Sejpal DV, Trindade AJ. Management of upper GI bleeding in patients with COVID-19 pneumonia. Gastrointest Endosc. 2020;S00165107(20)34181-X. https://doi.org/10.1016/j. gie.2020.04.028. Epub 2020 Apr 20.

91 Gulen M, Satar S. Uncommon presentation of COVID-19: gastrointestinal bleeding. Clin Res Hepatol Gastroenterol. 2020;S22107401(20)30139-X. https://doi.org/10.1016/j. clinre.2020.05.001. Epub 2020 May 21.

92 Lanas A, Dumonceau JM, Hunt RH, et al. Non-variceal upper gastrointestinal bleeding. Nat Rev Dis Primers. 2018;4:18020.
93 Massironi S, Viganò C, Dioscoridi L, et al. Endoscopic findings in patients infected with 2019 novel coronavirus in Lombardy, Italy. Clin Gastroenterol Hepatol. 2020;S1542-3565(20)30752-7. https://doi. org/10.1016/j.cgh.2020.05.045. Epub 2020 May 29.

94 Chan KH, Lim SL, Damati A, et al. Coronavirus disease 2019 (COVID-19) and ischemic colitis: an under-recognized complication. Am J Emerg Med. 2020;S07356757(20)30432-0. https://doi.org/10.1016/j. ajem.2020.05.072. Epub 2020 May 27.

95 Farina D, Rondi P, Botturi E, Renzulli M, Borghesi A, Guelfi D, et al. Gastrointestinal: bowel ischemia in a suspected coronavirus disease (COVID-19) patient [published online ahead of print, 2020 May 25]. J Gastroenterol Hepatol. 2020 May;jgh.15094.

96 Connors JM, Levy JH. COVID-19 and its implications for thrombosis and anticoagulation. Blood. 2020 Jun;135(23):2033-40.

97 Levi M, Thachil J, Iba T, Levy JH. Coagulation abnormalities and thrombosis in patients with COVID-19. Lancet Haematol. 2020 Jun;7(6):e438-40.

98 Artifoni M, Danic G, Gautier G, Gicquel P, Boutoille D, Raffi F, et al. Systematic assessment of venous thromboembolism in COVID-19 patients receiving thromboprophylaxis: incidence and role of $\mathrm{D}$-dimer as predictive factors. J Thromb Thrombolysis. 2020 Jul;50(1):211-6.

99 Toews I, George AT, Peter JV, et al. Interventions for preventing upper gastrointestinal bleeding in people admitted to intensive care units. Cochrane Database Syst Rev. 2018;6(6):CD008687.

100 Schmiderer A, Schwaighofer H, Niederreiter L, Profanter C, Steinle H, Ziachehabi A, et al. Decline in acute upper gastrointestinal bleeding during Covid-19 pandemic after lockdown in Austria [published online ahead of print, 2020 May 14]. Endoscopy. 2020 May;https://doi.org/10.1055/a-11784656.

101 Kim J, Doyle JB, Blackett JW, May B, Hur C, Lebwohl B, et al.; HIRE study group. Effect of the Coronavirus 2019 Pandemic on Outcomes for Patients Admitted With Gastrointestinal Bleeding in New York City [published online ahead of print, 2020 May 13] Gastroenterology. 2020 Sep;159(3):11551157.e1.

102 Rouillard S, Liu VX, Corley DA. COVID-19: long-term planning for procedure-based specialties during extended mitigation and suppression strategies. Gastroenterology. 2020 May. https://doi.org/10.1053/j.gastro.2020.05.047. Epub 2020 May 18.

103 Holtmann G, Quigley EM, Shah A, Camilleri M, Tan VP, Gwee KA, et al. "It ain't over ... till it's over!" Risk-mitigation strategies for patients with gastrointestinal diseases in the aftermath of the COVID-19 pandemic. J Gastroenterol Hepatol. 2020 Jul;35(7): 1117-23. 
104 Rutter MD, Brookes M, Lee TJ, et al. Impact of the COVID-19 pandemic on UK endoscopic activity and cancer detection: a National Endoscopy Database Analysis. Gut. 2020 Jul 20;gutjnl-2020-322179. https://doi.org/10.1136/gutjnl-2020322179. Epub.

105 Parasa S, Reddy N, Faigel DO, Repici A, Emura F, Sharma P. Global impact of the COVID-19 pandemic on endoscopy: an international survey of 252 centers from 55 countries. Gastroenterology. 2020 Jun 11:S0016-5085(20)34761-2. https://doi. org/10.1053/j.gastro.2020.06.009. Epub.

106 Lai A, Pasea L, Banerjee A, et al. Estimating excess mortality in people with cancer and multimorbidity in the COVID-19 emergency. BMJ Open. 2020. https://doi. org/10.13140/RG.2.2.34254.82242.

107 Guidance. COVID-19 personal protective equipment (PPE). Updated 18 June 2020 [cited 2020 Jun 26]. Available from: https:// www.gov.uk/government/publications/wuhan-novel-coronavirus-infection-prevention-and-control/covid-19-personal-protective-equipment-ppe

108 Rees CJ, East JE, Oppong K, et al. Restarting gastrointestinal endoscopy in the deceleration and early recovery phases of COVID-19 pandemic: guidance from the British Society of Gastroenterology. Clin Med (Lond). 2020 Jun 9;clinmed.2020-0296. https://doi. org/10.7861/clinmed.2020-0296. Epub.

109 Chiu PW, Ng SC, Inoue H, Reddy DN, Ling $\mathrm{Hu}$ E, Cho JY, et al. Practice of endoscopy during COVID-19 pandemic: position statements of the Asian Pacific Society for Digestive Endoscopy (APSDE-COVID statements). Gut. 2020 Jun;69(6):991-6.

110 Gralnek IM, Hassan C, Beilenhoff U, Antonelli G, Ebigbo A, Pellisè M, et al. ESGE and ESGENA Position Statement on gastrointestinal endoscopy and the COVID-19 pandemic. Endoscopy. 2020 Jun;52(6):48390.

111 Bhandari P, Subramaniam S, Bourke MJ, et al. Recovery of endoscopy services in the era of COVID-19: recommendations from an international Delphi consensus. Gut. 2020 Aug 14;gutjnl-2020-322329. https://doi. org/10.1136/gutjnl-2020-322329. Epub.

112 Repici A, Aragona G, Cengia G, Cantù P, Spadaccini M, Maselli R, Carrara S, Anderloni A, Fugazza A, Pace F, Rösch T; Italian GI-COVID19 Working Group. Low risk of covid-19 transmission in GI endoscopy. Gut. 2020 Apr 22:gutjnl-2020-321341. https://doi.org/10.1136/gutjnl-2020321341. Epub.

113 Calderwood AH, Day LW, Muthusamy VR, Collins J, Hambrick RD 3rd, Brock AS, et al.; ASGE Quality Assurance in Endoscopy Committee. ASGE guideline for infection control during GI endoscopy. Gastrointest Endosc. 2018 May;87(5):1167-79.

114 Hayee B, Thoufeeq M, Rees CJ, Penman I, East J. Safely restarting GI endoscopy in the era of COVID-19. Gut. 2020 Jun 5;gutjnl2020-321688. https://doi.org/10.1136/ gutjnl-2020-321688. Epub.

115 Han J, Wang Y, Zhu L et al. Preventing the spread of COVID-19 in digestive endoscopy during the resuming period: meticulous execution of screening procedures. Gastrointest Endosc. 2020; https://doi.org/10.1016/j. gie.2020.03.3855.

116 AGIP Council Guidance in Relation to GI Physiology Provision during the COVID-19 Pandemic. https://www.bsg.org.uk/covid19-advice/agip-council-guidance-in-relation-to-gi-physiology-provision-duringthe-covid-19-pandemicl [accessed 26th June 2020]

117 Zang R, Gomez Castro MF, McCune BT, Zeng Q, Rothlauf PW, Sonnek NM, et al. TMPRSS2 and TMPRSS4 promote SARS$\mathrm{CoV}-2$ infection of human small intestinal enterocytes. Sci Immunol. 2020 May; 5(47):eabc3582. https://doi.org/10.1126/sciimmunol.abc3582.

118 Wölfel R, Corman VM, Guggemos W, Seilmaier M, Zange S, Müller MA, et al. Virological assessment of hospitalized patients with COVID-2019. Nature. 2020 May; 581(7809):465-9.

119 Xiao F, Sun J, Xu Y, Li F, Huang X, Li H, et al. Infectious SARS-CoV-2 in Feces of Patient with Severe COVID-19 [Online ahead of print.]. Emerg Infect Dis. 2020 Aug;26(8): 1920-2.

120 Joint guidance on performing CT colonography in the early recovery phase of the Covid-19 pandemic. https://www.bsgar.org/ static/uploads/Joint\%20guidance $\% 20$ on $\% 20$ performing $\% 20$ C Tcolonography\%20in\%20the\%20earlyrecoveryphases\%20of\%20Covid.pdf [accessed 26th June 2020]

121 Lui RN, Wong SH, Sánchez-Luna SA, Pellino G, Bollipo S, Wong MY, et al. Overview of guidance for endoscopy during the coronavirus disease 2019 pandemic. J Gastroenterol Hepatol. 2020 May;35(5):749-59.

122 https://www.bsg.org.uk/covid-19-advice/ bsg-multi-society-guidance-on-further-recovery-of-endoscopy-services-during-thepost-pandemic-phase-of-covid-19/

123 Hayee B; SCOTS project group, East J, Rees CJ, Penman I. Multicentre prospective study of COVID-19 transmission following outpatient GI endoscopy in the UK. Gut. 2020 Sep 14;gutjnl-2020-322730. https://doi. org/10.1136/gutjnl-2020-322730. Epub.

124 Rees CJ, Rutter MD, Sharp L, Hayee B, East JE, Bhandari P, Penman I. COVID-19 as a barrier to attending for gastrointestinal endoscopy: weighing up the risks. Lancet Gastroenterol Hepatol. 2020 Sep 1;S24681253(20)30268-5. https://doi.org/10.1016/ S2468-1253(20)30268-5. Epub.

125 Armellini E, Repici A, Alvisi C, Dinelli M, Gambitta P, Manes G, et al.; Fast Track Endoscopy Study Group. Analysis of patients attitude to undergo urgent endoscopic pro- cedures during COVID-19 outbreak in Italy. Dig Liver Dis. 2020 Jul;52(7):695-9.

126 Klein WM, Ferrer RA, Kaufman AR. How (or Do) People "Think" About Cancer Risk, and Why That Matters [Online ahead of print.]. JAMA Oncol. 2020 Jul;6(7):983-4.

127 https://www.cdc.gov/coronavirus/2019ncov/hcp/non-us-settings/public-healthmanagement-hcw-exposed.html

128 Laszlo HE, Seward E, Ayling R, et al. Quantitative faecal immunochemical test for patients with high risk bowel symptoms: a prospective cohort study. medRxiv 2020.05.10.20096941; doi: https://doi.org/ https://doi.org/10.1101/2020.05.10.20096 941.

129 Nicholson BD, James T, Paddon M, Justice S, Oke JL, East JE, et al. Faecal immunochemical testing for adults with symptoms of colorectal cancer attending English primary care: a retrospective cohort study of 14,487 consecutive test requests. Aliment Pharmacol Ther. https://doi.org/10.1111/apt.15969. Epub 2020 Jul.

130 Loveday C, Sud A, Jones M, et al. Prioritisation by FIT to mitigate the impact of delays in the 2-week wait colorectal cancer referral pathway during the COVID-19 pandemic: a UK modelling study. Gut. 2020 Aug 27;gutjnl-2020-321650. https://doi.org/ 10.1136/gutjnl-2020-321650. Epub.

131 Lamb CA, Kennedy NA, Raine T, Hendy PA, Smith PJ, Limdi JK, et al.; IBD guidelines eDelphi consensus group. British Society of Gastroenterology consensus guidelines on the management of inflammatory bowel disease in adults. Gut. 2019 Dec;68 Suppl 3:s1106.

132 Gov.UK. COVID-19: guidance for health professionals. Available from: https://www. gov.uk/government/collections/wuhannovel-coronavirus

133 NICE. Coronavirus (COVID-19). Available from: https://www.nice.org.uk/COVID-19

134 NIH. Coronavirus disease 2019 (COVID-19) treatment guidelines. Available from: https://www.covid19 treatmentguidelines.nih.gov

135 Sultan S, Altayar O, Siddique SM, Davitkov P, Feuerstein JD, Lim JK, et al.; AGA Institute. Electronic address: ewilson@gastro. org. AGA Institute Rapid Review of the Gastrointestinal and Liver Manifestations of COVID-19, Meta-Analysis of International Data, and Recommendations for the Consultative Management of Patients with COVID-19. Gastroenterology. 2020 Jul; 159(1):320-334.e27.

136 Frommeyer G, Fischer C, Ellermann C, Lange PS, Dechering DG, Kochhäuser S, et al. Severe Proarrhythmic Potential of the Antiemetic Agents Ondansetron and Domperidone. Cardiovasc Toxicol. 2017 Oct; 17(4):451-7.

137 Anand S, Mande SS. Diet, microbiota and gut-lung connection. Front Microbiol. 2018; 9:2147. 
138 Groves HT, Higham SL, Moffatt MF, Cox MJ, Tregoning JS. Respiratory viral infection alters the gt microbiota by inducing inappetence. MBio. 2020 Feb; 11(1): e03236-19.

139 Gu S, Chen Y, Wu Z, Chen Y, Gao H, Lv L, et al. Alterations of the gut microbiota in patients with COVID-19 or H1N1 influenza. Clin Infect Dis. 2020 Jun;ciaa709. Epub.

$140 \mathrm{Xu}$ K, Cai H, Shen Y, Ni Q, Chen Y, Hu S, et al. Management of corona virus disease-19 (COVID-19): the Zhejiang experience. J Zhejiang Univ Med Sci. 2020 Feb;41(1):14757. Chinese.

141 Zuo T, Zhang F, Lui GC, Yeoh YK, Li AY, Zhan $\mathrm{H}$, et al. Alterations in Gut Microbiota of Patients With COVID-19 During Time of Hospitalization. Gastroenterology. 2020 Sep;159(3):944-955.e8.

142 Di Renzo L, Merra G, Esposito E, De Lorenzo A. Are probiotics effective adjuvant therapeutic choice in patients with COVID-19? Eur Rev Med Pharmacol Sci. 2020 Apr; 24(8):4062-3.

143 King S, Glanville J, Sanders ME, Fitzgerald A, Varley D. Effectiveness of probiotics on the duration of illness in healthy children and adults who develop common acute respiratory infectious conditions: a systematic review and meta-analysis. Br J Nutr. 2014 Jul;112(1):41-54.

144 Morrow LE, Kollef MH, Casale TB. Probiotic prophylaxis of ventilator-associated pneumonia: a blinded, randomized, controlled trial. Am J Respir Crit Care Med. 2010 Oct;182(8):1058-64.

145 Zeng J, Wang CT, Zhang FS, Qi F, Wang SF, $\mathrm{Ma} S$, et al. Effect of probiotics on the incidence of ventilator-associated pneumonia in critically ill patients: a randomized controlled multicenter trial. Intensive Care Med. 2016 Jun;42(6):1018-28.

146 Mak JW, Chan FK, Ng SC. Probiotics and COVID-19: one size does not fit all. Lancet Gastroenterol Hepatol. 2020 Jul;5(7):644-5.

147 Ianiro G, Mullish BH, Kelly CR, Sokol H, Kassam Z, Ng SC, et al. Screening of faecal microbiota transplant donors during the COVID-19 outbreak: suggestions for urgent updates from an international expert panel. Lancet Gastroenterol Hepatol. 2020 May; 5(5):430-2.

148 Neurath MF. COVID-19 and immunomodulation in IBD. Gut. 2020 Jul;69(7):1335-42.

149 Allocca M, Fiorino G, Zallot C, Furfaro F, Gilardi D, Radice S, et al. Incidence and patterns of COVID-19 among inflammatory bowel disease patients from the Nancy and Milan cohorts. Clin Gastroenterol Hepatol. 2020 Aug;18(9):2134-5.

150 Monteleone G, Ardizzone S. Are patients with inflammatory bowel disease at increased risk for Covid-19 infection? J Crohn's Colitis. 2020 Sep;14(9):1334-6.

151 Taxonera C, Sagastagoitia I, Alba C, Mañas N, Olivares D, Rey E. Novel coronavirus disease (COVID-19) in patients with inflam- matory bowel diseases. Aliment Pharmacol Ther. 2020 Jul;52(2):275-83.

152 Dolinger MT, Person H, Smith R, Jarchin L, Pittman N, Dubinsky MC, et al. Pediatric Crohn disease and multisystem inflammatory syndrome in children (MIS-C) and COVID-19 treated with infliximab. J Pediatr Gastroenterol Nutr. 2020 Aug;71(2):153-5.

153 Kappelman MK, Brenner EJ, Colombel JF, Ungaro R. Coronavirus and IBD reporting database: surveillance epidemiology of coronavirus under research exclusion (SECUREIBD). 2020. Available from: https://covidibdorg

154 Al-Shamsi HO, Alhazzani W, Alhuraiji A, Coomes EA, Chemaly RF, Almuhanna M, et al. A Practical Approach to the Management of Cancer Patients During the Novel Coronavirus Disease 2019 (COVID-19) Pandemic: An International Collaborative Group. Oncologist. 2020 Jun;25(6):e936-45.

155 Di Fiore F, Bouche O, Lepage C, Sefrioui D, Gangloff A, Schwarz L, et al. COVID-19 epidemic: proposed alternatives in the management of digestive cancers: a French intergroup clinical point of view (SNFGE, FFCD, GERCOR, UNICANCER, SFCD, SFED, SFRO, SFR). Dig Liver Dis. 2020 Jun;52(6): 597-603.

156 Tchelebi LT, Haustermans K, Scorsetti M, Hosni A, Huguet F, Hawkins MA, et al. Recommendations for the use of radiation therapy in managing patients with gastrointestinal malignancies in the era of COVID-19. Radiother Oncol. 2020 Jul;148:194-200.

157 Castro Filho EC, Castro R, Fernandes FF, Pereira G, Perazzo H. Gastrointestinal endoscopy during the COVID-19 pandemic: an updated review of guidelines and statements from international and national societies. Gastrointest Endosc. 2020 Aug;92(2): 440-445.e6.

158 Scarpignato C, Gatta L, Zullo A, Blandizzi C; SIF-AIGO-FIMMG Group; Italian Society of Pharmacology, the Italian Association of Hospital Gastroenterologists, and the Italian Federation of General Practitioners. Effective and safe proton pump inhibitor therapy in acid-related diseases - A position paper addressing benefits and potential harms of acid suppression. BMC Med. 2016 Nov; 14(1):179.

159 Patel P, Sengupta N. PPIs and beyond: a framework for managing anticoagulationrelated gastrointestinal bleeding in the era of COVID-19. Dig Dis Sci. 2020 Aug;65(8): 2181-6.

160 Agewall S, Cattaneo M, Collet JP, Andreotti F, Lip GY, Verheugt FW, et al. Expert position paper on the use of proton pump inhibitors in patients with cardiovascular disease and antithrombotic therapy. Eur Heart J. 2013 Jun;34(23):1708-13.

161 Almario CV, Chey WD, Spiegel BMR. Increased risk of COVID-19 among users of proton pump inhibitors. Am J Gastroenterol. Epub 2020 Aug 25.
162 Luxenburger H, Sturm L, Biever P, Rieg S, Duerschmied D, Schultheiss M, et al. Treatment with proton pump inhibitors increases the risk of secondary infections and ARDS in hospitalized patients with COVID-19: coincidence or underestimated risk factor? J Intern Med. Epub 2020 Jul 1.

163 Lee SW, Ha EK, Yeniova AÖ, et al. Severe clinical outcomes of COVID-19 associated with proton pump inhibitors: a nationwide cohort study with propensity score matching. Gut. 2020;gutjnl-2020-322248. https:// doi.org/10.1136/gutjnl-2020-322248. Epub 2020 Jul 30.

164 Scarpignato C, Sloan JA, Wang DH, Hunt RH. Gastrointestinal pharmacology: practical tips for the esophagologist [published online ahead of print, 2020 Aug 21]. Ann N Y Acad Sci. 2020 Aug;nyas.14447.

165 Touret F, Gilles M, Barral K, et al. In vitro screening of a FDA approved chemical library reveals potential inhibitors of SARS CoV-2 replication. Sci Rep. 2020;10(1): 13093.

166 Ray A, Sharma S, Sadasivam B. The Potential Therapeutic Role of Proton Pump Inhibitors in COVID-19: Hypotheses Based on Existing Evidences [published online ahead of print, 2020 Sep 2]. Drug Res (Stuttg). 2020 Oct;70(10):484-8.

167 Taştemur Ş, Ataseven H. Is it possible to use proton pump inhibitors in COVID-19 treatment and prophylaxis? Med Hypotheses. 2020 Oct; $143: 110018$

168 Sasaki T, Nakayama K, Yasuda H, Yoshida M, Asamura T, Ohrui T, et al. A randomized, single-blind study of lansoprazole for the prevention of exacerbations of chronic obstructive pulmonary disease in older patients. J Am Geriatr Soc. 2009 Aug;57(8): 1453-7.

169 Blanc F, Waechter C, Vogel T, et al. Interest of proton pump inhibitors in reducing the occurrence of COVID-19: a case-control study. Preprints. 2020; DOI: https://doi. org/10.20944/preprints202005.0016.v1.]

170 Wu C, Liu Y, Yang Y, Zhang P, Zhong W, Wang Y, et al. Analysis of therapeutic targets for SARS-CoV-2 and discovery of potential drugs by computational methods. Acta Pharm Sin B. 2020 May; 10(5):766-88.

171 Sen Gupta PS, Biswal S, Singha D, Rana MK Binding insight of clinically oriented drug famotidine with the identified potential target of SARS-CoV-2. J Biomol Struct Dyn. Epub 2020 Jun 24.

172 Mather JF, Seip RL, McKay RG. Impact of Famotidine Use on Clinical Outcomes of Hospitalized Patients With COVID-19. Am J Gastroenterol. 2020 Oct;115(10):1617-23. ; Epub ahead of print.

173 Cheung KS, Hung IF, Leung WK. Association between famotidine use and COVID-19 severity in Hong Kong: a territory-wide study. Gastroenterology. S0016-5085(20) 34940-4. https://doi.org/10.1053/j.gastro. 2020.05.098. Epub 2020 Jul 16. 
174 Singh VP, El-Kurdi B, Rood C. What underlies the benefit of famotidine formulations used during COVID-19? Gastroenterology. S0016-5085(20)35020-4. https://doi. org/10.1053/j.gastro.2020.07.051. Epub 2020 Aug 7.

175 Malone RW, Tisdall P, Fremont-Smith P, Liu Y, Huang XP, White KM, et al. COVID-19: famotidine, histamine, mast cells, and mechanisms. Res Sq [Preprint]. 2020 Jun 22:rs.3.rs-30934. https://doi. org/10.21203/rs.3.rs-30934/v2.

176 Hogan RB II, Hogan RB III, Cannon T, Rappai M, Studdard J, Paul D, et al. Dual-histamine receptor blockade with cetirizine: famotidine reduces pulmonary symptoms in COVID-19 patients. Pulm Pharmacol Ther. 2020 Aug;63:101942.

177 Garrido I, Liberal R, Macedo G. Review article: COVID-19 and liver disease-what we know on 1st May 2020. Aliment Pharmacol Ther. 2020 Jul;52(2):267-75.

178 Xu Z, Shi L, Wang Y, Zhang J, Huang L, Zhang C, et al. Pathological findings of COVID-19 associated with acute respiratory distress syndrome. Lancet Respir Med. 2020 Apr;8(4):420-2.

179 Jaeschke H. Acetaminophen: Dose-Dependent Drug Hepatotoxicity and Acute Liver Failure in Patients. Dig Dis. 2015;33(4):46471.

180 Meunier L, Larrey D. Recent Advances in Hepatotoxicity of Non Steroidal Anti-Inflammatory Drugs. Ann Hepatol. 2018 Mar; 17(2):187-91.

181 Agarwal A, Chen A, Ravindran N, To C, Thuluvath PJ. Gastrointestinal and Liver Manifestations of COVID-19. J Clin Exp Hepatol. 2020 May-Jun;10(3):263-5.

182 Parohan M, Yaghoubi S, Seraj A. Liver injury is associated with severe coronavirus disease 2019 (COVID-19) infection: a systematic review and meta-analysis of retrospective studies. Hepatol Res. 2020 May 9. https://doi.org/10.1111/hepr.13510.

183 Youssef M, H Hussein M, Attia AS, M Elshazli R, Omar M, Zora G, et al. COVID-19 and liver dysfunction: A systematic review and meta-analysis of retrospective studies. J Med Virol. 2020 May;92(10):1825-33.

184 Qiao W, Wang C, Chen B, Zhang F, Liu Y, $\mathrm{Lu} \mathrm{Q}$, et al. Ibuprofen attenuates cardiac fibrosis in streptozotocin-induced diabetic rats. Cardiology. 2015;131(2):97-106.

185 WHO. The use of non-steroidal anti-inflammatory drugs (NSAIDs) in patients with COVID-19. Scientific brief. 2020. Available from: https://appswhoint/iris/bitstream/ handle/10665/331796/WHO-2019-nCoVSci_Brief-NSAIDs-20201-engpdf
186 EMA. EMA gives advice on the use of nonsteroidal anti-inflammatories for COVID-19. 2020. Available from: https://europeanpainfederationeu/wp-content/uploads/2020/04/EMA-NSAIDspdf

187 Kirkby NS, Zaiss AK, Wright WR, Jiao J, Chan MV, Warner TD, et al. Differential COX-2 induction by viral and bacterial PAMPs: consequences for cytokine and interferon responses and implications for antiviral COX-2 directed therapies. Biochem Biophys Res Commun. 2013 Aug;438(2): 249-56.

188 Amici C, Di Caro A, Ciucci A, Chiappa L, Castilletti C, Martella V, et al. Indomethacin has a potent antiviral activity against SARS coronavirus. Antivir Ther. 2006;11(8): 1021-30.

189 Hung IF, To KK, Chan JF, Cheng VC, Liu KS, Tam A, et al. Efficacy of ClarithromycinNaproxen-Oseltamivir Combination in the Treatment of Patients Hospitalized for Influenza A(H3N2) Infection: An Open-label Randomized, Controlled, Phase IIb/III Trial. Chest. 2017 May;151(5):1069-80.

190 Naksuk N, Lazar S, Peeraphatdit TB. Cardiac safety of off-label COVID-19 drug therapy: a review and proposed monitoring protocol. Eur Heart J Acute Cardiovasc Care. 2020 Apr;9(3):215-21.

191 Tisdale JE, Jaynes HA, Kingery JR, Mourad NA, Trujillo TN, Overholser BR, et al. Development and validation of a risk score to predict QT interval prolongation in hospitalized patients. Circ Cardiovasc Qual Outcomes. 2013 Jul;6(4):479-87.

192 Jankelson L, Karam G, Becker ML, Chinitz LA, Tsai MC. QT prolongation, torsades de pointes, and sudden death with short courses of chloroquine or hydroxychloroquine as used in COVID-19: A systematic review. Heart Rhythm. 2020 Sep;17(9):1472-9.

193 Saleh M, Gabriels J, Chang D, Soo Kim B, Mansoor A, Mahmood E, et al. Effect of chloroquine, hydroxychloroquine, and azithromycin on the corrected QT interval in patients with SARS-CoV-2 infection. Circ Arrhythm Electrophysiol. 2020 Jun; 13(6):e008662.

194 Giudicessi JR, Noseworthy PA, Friedman PA, Ackerman MJ. Urgent Guidance for Navigating and Circumventing the QTcProlonging and Torsadogenic Potential of Possible Pharmacotherapies for Coronavirus Disease 19 (COVID-19). Mayo Clin Proc. 2020 Jun;95(6):1213-21.

195 Ferrario CM, Jessup J, Chappell MC, Averill $\mathrm{DB}$, Brosnihan KB, Tallant EA, et al. Effect of angiotensin-converting enzyme inhibition and angiotensin II receptor blockers on cardiac angiotensin-converting enzyme 2 . Circulation. 2005 May;111(20):2605-10.
196 Soler MJ, Ye M, Wysocki J, William J, Lloveras J, Batlle D. Localization of ACE2 in the renal vasculature: amplification by angiotensin II type 1 receptor blockade using telmisartan. Am J Physiol Renal Physiol. 2009 Feb;296(2):F398-405.

197 Jarcho JA, Ingelfinger JR, Hamel MB D'Agostino RB Sr, Harrington DP. Inhibitors of the Renin-Angiotensin-Aldosterone System and Covid-19. N Engl J Med. 2020 Jun;382(25):2462-4.

198 Guo X, Zhu Y, Hong Y. Decreased mortality of COVID-19 with renin-angiotensin-aldosterone system inhibitors therapy in patients with hypertension: a meta-analysis. Hypertension. 2020 May 27. https://doi. org/10.1161/HYPERTENSIONAHA. 120 . 15572.

199 ECC. Position statement of the ESC Council on Hypertension on ACE-inhibitors and angiotensin receptor blockers. 2020. Available from: https://wwwescardioorg/Councils/ Council-on-Hypertension-(CHT)/News/ position-statement-of-the-esc-council-onhypertension-on-ace-inhibitors-and-ang

200 ACC. HFSA/ACC/AHA statement addresses concerns re: using RAAS antagonists in COVID-19. 2020. Available from: https:// wwwaccorg/latest-in-cardiology/articles/2020/03/17/08/59/hfsa-acc-aha-statement-addresses-concerns-re-using-raasantagonists-in-covid-19

201 Vaduganathan M, Vardeny O, Michel T, McMurray JJ, Pfeffer MA, Solomon SD. Renin-Angiotensin-Aldosterone System Inhibitors in Patients with Covid-19. N Engl J Med. 2020 Apr;382(17):1653-9.

202 Iddir M, Brito A, Dingeo G, Fernandez Del Campo SS, Samouda H, La Frano MR, et al. Strengthening the Immune System and Reducing Inflammation and Oxidative Stress through Diet and Nutrition: considerations during the COVID-19 Crisis. Nutrients. 2020 May;12(6):1562.

203 Schwalfenberg GK. A review of the critical role of vitamin $\mathrm{D}$ in the functioning of the immune system and the clinical implications of vitamin $\mathrm{D}$ deficiency. Mol Nutr Food Res. 2011 Jan;55(1):96-108.

204 Laird E, Rhodes J, Kenny RA. Vitamin D and Inflammation: Potential Implications for Severity of Covid-19. Ir Med J. 2020 May; 113(5):81.

205 Grant WB, Lahore H, McDonnell SL, et al. Evidence that vitamin D supplementation could reduce risk of influenza and COVID-19 infections and deaths. Nutrients. 2020;12(4):988. 